Subscriber access provided by CORNELL UNIVERSITY LIBRARY

\title{
Article
}

\section{PEGylation of reduced graphene oxide induces toxicity in cells of the blood-brain barrier: an in vitro and in vivo study}

Monique Culturato Padilha Mendonça, Edilene Siqueira Soares, Marcelo Bispo de Jesus,

Helder José Ceragioli, Ângela Giovana Batista, Ádám Nyúl-Tóth, Judit Molnár, Imola

Wilhelm, Mario Roberto Marostica Junior, Istvan Krizbai, and Maria Alice da Cruz-Hofling

Mol. Pharmaceutics, Just Accepted Manuscript • DOI: 10.1021/acs.molpharmaceut.6b00696 • Publication Date (Web): 06 Oct 2016

Downloaded from http://pubs.acs.org on October 8, 2016

\section{Just Accepted}

"Just Accepted" manuscripts have been peer-reviewed and accepted for publication. They are posted online prior to technical editing, formatting for publication and author proofing. The American Chemical Society provides "Just Accepted" as a free service to the research community to expedite the dissemination of scientific material as soon as possible after acceptance. "Just Accepted" manuscripts appear in full in PDF format accompanied by an HTML abstract. "Just Accepted" manuscripts have been fully peer reviewed, but should not be considered the official version of record. They are accessible to all readers and citable by the Digital Object Identifier (DOI $\left.{ }^{\circ}\right)$. "Just Accepted" is an optional service offered to authors. Therefore, the "Just Accepted" Web site may not include all articles that will be published in the journal. After a manuscript is technically edited and formatted, it will be removed from the "Just Accepted" Web site and published as an ASAP article. Note that technical editing may introduce minor changes to the manuscript text and/or graphics which could affect content, and all legal disclaimers and ethical guidelines that apply to the journal pertain. ACS cannot be held responsible for errors or consequences arising from the use of information contained in these "Just Accepted" manuscripts. 


\title{
PEGylation of reduced graphene oxide induces toxicity in cells of the
}

\section{blood-brain barrier: an in vitro and in vivo study}

\author{
Monique Culturato Padilha Mendonça ${ }^{1,2^{*}}$, Edilene Siqueira Soares ${ }^{2}$, Marcelo Bispo de Jesus ${ }^{2}$, \\ Helder José Ceragioli ${ }^{3}$, Ângela Giovana Batista ${ }^{4}$, Ádám Nyúl-Tóth ${ }^{5}$, Judit Molnár ${ }^{5}$, Imola \\ Wilhelm ${ }^{5}$ Mário Roberto Maróstica Júnior ${ }^{4}$, István Krizbai ${ }^{5,6}$, Maria Alice da Cruz-Höfling ${ }^{1,2}$ \\ ${ }^{1}$ Department of Pharmacology, Faculty of Medical Sciences; State University of Campinas, Campinas, \\ SP, Brazil \\ ${ }^{2}$ Department of Biochemistry and Tissue Biology, Institute of Biology; State University of Campinas, \\ Campinas, SP, Brazil \\ 3 Department of Semiconductors, Instruments and Photonics, Faculty of Electrical and Computer \\ Engineering; State University of Campinas, Campinas, SP, Brazil \\ 4 Department of Food and Nutrition, School of Food Engineerig, State University of Campinas, \\ Campinas, SP, Brazil \\ ${ }^{5}$ Institute of Biophysics, Biological Research Centre, Hungarian Academy of Sciences, Szeged, Hungary \\ 6 Vasile Goldis Western University, Arad, Romania.
}

*Corresponding author: mo_padilha@hotmail.com; +55 (19) 3521-6250; Department of Pharmacology, Faculty of Medical Sciences, State University of Campinas, 13083-881, Campinas, SP, Brazil.

\begin{abstract}
Polyethylene glycol (PEG) coating has been frequently used to improve the pharmacokinetic behavior of nanoparticles. Studies which contribute to better unravel the effects of PEGylation on the toxicity of nanoparticle formulation are therefore highly relevant. In the present study, reduced graphene oxide (rGO) was functionalized with PEG and its effects on key components of the blood-brain barrier, such as
\end{abstract}


astrocytes and endothelial cells, were analyzed in culture and in an in vivo rat model. The in vitro studies demonstrated concentration-dependent toxicity. The highest concentration $(100 \mu \mathrm{g} / \mathrm{ml})$ of non-PEGylated rGO had a lower toxic influence on cell viability in primary cultures of astrocytes and rat brain endothelial cells (RBECs), while PEGylated rGO induced deleterious effects and cell death. We assessed hippocampal $\mathrm{BBB}$ integrity in vivo by evaluating astrocyte activation and the expression of the endothelial tight and adherens junctions proteins. From $1 \mathrm{~h}$ to 7 days post-rGO-PEG systemic injection, a notable and progressive down-regulation of protein markers of astrocytes (GFAP, connexin-43), the endothelial tight (occludin) and adherens ( $\beta$ catenin) junctions, and basal lamina (laminin) were observed. The formation of intracellular ROS demonstrated by increases in the enzymatic antioxidant system in the PEGylated rGO samples was indicative of oxidative stress-mediated damage. Under the experimental conditions and design of the present study the PEGylation of rGO did not improve interaction with components of the blood-brain barrier. In contrast, the attachment of PEG to rGO induced deleterious effects in comparison with the effects caused by non-PEGylated rGO.

KEYWORDS: PEGylation, graphene-based nanomaterials, central nervous system, Nanotoxicity

\section{INTRODUCTION}

Since its discovery in 2004, graphene and derivatives, such as graphene oxide (GO) and reduced graphene oxide (rGO), have been extensively studied in many different fields. Their remarkable electronic, optical, magnetic, thermal and mechanical properties lead to the broad-spectrum application of these nanomaterials in 
neuroscience, biomedicine, bioimaging, biosensor development, drug/gene delivery, photothermal therapy and tissue engineering [1-4].

Typically, the nanomaterial surface can be tailored through chemical modification to enhance such properties. One of the mostcommon of these modifications is PEGylation, which is the process of the covalent and non-covalent attachment of polyethylene glycol (PEG) molecules to the surface of nanomaterials. PEG is a polymer composed of repetitive subunits of ethylene ether, available in different molecular masses, variable branched chain lengths and terminal functional groups. The attachment of PEG improves the stability and solubility of nanomaterials in physiological solutions and reduces their accumulation in the reticuloendothelial system, thus prolonging blood circulation half-life and improving pharmacokinetic behavior $[5,6]$. Conversely, some studies have identified minimal benefits and even described detrimental effects on the improving nanoparticle circulation half-life [7], nanoparticle uptake and reductions in overall toxicity $[8,9]$. This may be due to a variety of physicochemical properties (e.g., size, surface charge, chemical composition and aggregation) that can be altered by PEGylation and significantly affecting the physiological interactions between nanomaterials and biological targets.

The interplay between PEGylated graphene-based nanomaterials and the central nervous system (CNS) are poorly understood, and details about their toxicological characteristics to support the rational design and development of new nanomaterials are lacking.

We have previously demonstrated that water-suspended rGO injected in rats through the tail vein (i.v.) induces a transient disruption of the paracellular tightness of the blood-brain barrier (BBB) in the hippocampus [10], with a relatively low toxicity for the vital organs [11]. The BBB is a dynamic interface that separates the 
peripheral circulating blood and the CNS microenvironment. The BBB plays a major role in the maintenance of the homeostasis of the brain by regulating ion traffic, entry of xenobiotics or potentially harmful molecules, and at the same time mediates the transport of nutrients to the brain parenchyma. Formed by specialized non-fenestrated vascular endothelial cells, the BBB is tightly controlled by astrocytes, pericytes embedded in the vascular basement membrane, microglia and neurons. The neurovascular unit consists of endothelium, astrocytes, pericytes and neurons, highlighting the close interconnection between the BBB and neural functionality [12, 13].

In the present study, we functionalized rGO with PEG and investigated its in vitro and in vivo effects on the BBB. By investigating the response of astrocytes and rat brain endothelial cells (RBECs) to non-PEGylated and PEGylated rGO we hope to provide a better understanding of the interactions between these graphene derivatives in living cells and organisms. The study will also contribute to an improved characterization of the effects of PEGylation on graphene-based nanomaterials.

\section{EXPERIMENTAL SECTION}

2.1 Chemicals. All chemicals used in rGO-PEG synthesis and cell culture were obtained from Sigma-Aldrich, unless stated otherwise.

2.2 rGO-PEG Synthesis and Characterization. The detailed synthesis of rGO was described previously [10]. Here, we aimed to functionalize rGO with PEG by simple mixing both in order to initiate physical adsorption. Briefly, an aqueous solution of PEG $6,000(1 \mathrm{mg} / \mathrm{ml})$ was prepared. The mixture was bath-sonicated for $15 \mathrm{~min}$ and the 
aqueous suspension of $\mathrm{rGO}(1 \mathrm{mg} / \mathrm{ml})$ was added to the solution (1:1). After incubation under ultrasonication for $30 \mathrm{~min}$ at room temperature, the solution contained the rGOPEG final product.

The PEGylation was further confirmed by Fourier-transform infrared spectroscopy in attenuated total reflectance mode (FTIR-ATR) using a FTIR Spectrophotometer (Shimadzu-8400S, Kyoto, Japan). Forty scans were taken with the resolution of $4 \mathrm{~cm}-1$ in the region of $4000-400 \mathrm{~cm}^{-1}$. The nuclear magnetic resonance (NMR) spectra of ${ }^{13} \mathrm{C}$ were recorded at room temperature under magic angle spinning with a Bruker Avance 300 spectrometer operating at $75 \mathrm{MHz}$. Thermogravimetric analyses (TGA) and differential scanning calorimetry (DSC) curves were recorded on Shimadzu TGA-50 and Shimadzu DSC-60 instruments, respectively, under nitrogen purge with a heating rate of $10^{\circ} \mathrm{C} / \mathrm{min}$.

Dynamic light scattering (DLS) technique was used for the measurement of size, polydispersity index (PDI) and zeta potential of the rGO-PEG suspension using a ZetaSizer Nano ZS 90 instrument (Malvern Instruments Ltd., Worcestershire, UK). The results were expressed as the average of three measurements.

Morphological analysis of the sample was done with field emission scanning electron microscope (FE-SEM) (Zeiss Supra 55 VP-SEM) and high-resolution transmission electron microscopy (HRTEM) using a JEOL JSM-6330F microscope operated at $300 \mathrm{kV}$ as previously described [10].

2.3 Cell culture. Isolation of astrocytes and RBECs was carried out following the national and international recommendations for the care and use of laboratory animals. 


\subsubsection{Astrocytes. Astrocytes were prepared from newborn Wistar rats (Rattus} norvegicus) by mechanical dissociation of the brain tissue and filtering through a cell strainer of $40 \mu \mathrm{m}$ pore size. Cells were cultured until confluence on poly-L-lysinecoated dishes and frozen in Bambanker cell freezing medium (Nippon Genetics). Before use, cells were plated into poly-L-lysine-coated 96-well plates or 8-well microscopy culture chambers (for immunofluorescence assays) and cultured until confluence. Cells were used at passage number P1.

2.3.2 RBECs. RBECs were prepared from three-week-old Wistar rats. Under sterile conditions, brains were gently dissected, and forebrains collected in ice-cold phosphate buffered saline (PBS). The meninges were carefully removed using sterile chromatography paper, cut into small pieces and digested in two enzymatic steps: (1) collagenase type 2 and DNAse I in DMEM/F12 (Life Technologies, Budapest, Hungary) at $37^{\circ} \mathrm{C}$ for 75 minutes, and (2) collagenase/dispase and DNAse I in $\mathrm{DMEM} / \mathrm{F} 12$ at $37^{\circ} \mathrm{C}$ for 50 minutes. Myelin was removed by centrifugation on $20 \%$ bovine serum albumin (BSA) between the two digestion steps. The digested microvessel fragments were separated on a continuous 33\% Percoll gradient and plated onto fibronectin/collagen type IV-coated dishes; 96-well plates, E-plates (ACEA Biosciences, San Diego, USA) or Transwell (\#3470; Corning Life Sciences, Corning, USA) permeable polyester filters ( $0.4 \mu \mathrm{m}$ pore size, $0.33-\mathrm{cm}^{2}$ surface area). Cells were maintained in DMEM/F12 containing 10\% plasma-derived serum (PDS, First Link, Wolverhampton, UK), $1 \mathrm{ng} / \mathrm{ml}$ basic fibroblast growth factor (Sigma Aldrich), 100 $\mu \mathrm{g} / \mathrm{ml}$ heparin, and $5 \mu \mathrm{g} / \mathrm{ml}$ insulin-transferrin-selenite at $37^{\circ} \mathrm{C}$ and $5 \% \mathrm{CO}_{2}$. In the first two days, $4 \mu \mathrm{g} / \mathrm{ml}$ puromycin was added to remove contaminating cells. Three days after isolation, RBECs reached confluence and were treated with $550 \mathrm{nM}$ 
hydrocortisone, $250 \mu \mu \mathrm{M} \quad$ CTP-cAMP $\quad$ and $\quad 17.5 \mu \mathrm{M} \quad 4-(3-$ butoxy-4methoxybenzyl)imidazolidin-2-one (RO-201724) to induce BBB characteristics [14].

2.4 Toxicity measurements. The in vitro concentration of rGO-PEG $(100 \mu \mathrm{g} / \mathrm{ml})$ was selected as a function of the concentration already used for in vivo experiments $(7 \mathrm{mg} / \mathrm{kg})[10,11]$. For the calculation, we considered a $200 \mathrm{~g}$ rat with blood volume average of $14 \mathrm{ml}$ [15]. We also used a concentration 10 times lower than the threshold concentration, able to induce oxidative stress and DNA damage in some cell lines [16].

2.4.1 EZ4U assay. Cell viability was detected using EZ4U assay (Biomedica Medizinprodukte, Vienna, Austria). Cells were seeded in 96-well coated plate (Corning Technologies, Corning, NY, USA) and after reaching confluence the cells were treated with culture medium (negative control), rGO-PEG or vehicle (PEG 6,000) for 3 h 30 $\min$ (RBECs) or $24 \mathrm{~h}$ (Astrocytes). For the sake of comparison, we also treated the cells with an aqueous suspension of rGO and its vehicle (sterile distilled water) using the same concentrations as for other treatments. After washing the cells with phenol-red free DMEM, the EZ4U assay was performed according to the manufacturer's instructions. The method is based on the reduction of tetrazolium salt to colored formazan by the mitochondria of living cells. The absorbance was recorded using a microplate reader (FLUOstar Optima; BMG Labtechnologies, Offenburg, Germany) at $492 \mathrm{~nm}$ and values were compared to control cells. To confirm that rGO-PEG was not able to spontaneously metabolize the EZ4U substrate, we also measured the response of rGO-PEG in the absence of cells. rGO-PEG alone was not able to reduce uncolored tetrazolium salts into intensely colored formazan derivate. 
2.4.2 Cell impedance measurements. Cell impedance was detected using the xCELLigence system (ACEA, San Diego, CA, USA). It is a cell-based label-free method that measures in real time electrical impedance across gold electrodes placed at the bottom of a 96-well plate (E-plate 96, ACEA Biosciences). Further, the xCELLigence software (version 1.2.1) converts the electrical impedance to a cell index (CI) value (arbitrary units). In general, under the same physiologic conditions, if more cells are attached to the electrodes, the impedance value is higher, leading to increased CI. Contrarily, in the absence of cells, i.e., cell death or toxicity-induced cell detachment; a lower CI value is obtained. The impedance depends on the tightness of the junctions as well.

Cells were seeded in E-plates and the impedance was continuously monitored until cells reached a steady phase (confluence and well-formed tight junctions in the case of RBECs), when they were treated with rGO or rGO-PEG. Impedance was monitored every $1 \mathrm{~h}$ during $24 \mathrm{~h}$.

2.5 Immunofluorescence (IF). Cells were fixed in 95\% ethanol/5\% acetic acid at $20^{\circ} \mathrm{C}$ for 5 minutes. After blocking with $3 \%$ BSA- for $30 \mathrm{~min}$, samples were incubated overnight with primary antibodies (Table 1). The staining was visualized using Alexa 594- (GFAP), Alexa 488- (Aquaporin-4, Occludin) or Cy5-conjugated (Claudin-5) secondary antibodies. Nuclear staining of the cells was carried out using Hoechst 33342. Images were recorded by a Nikon Eclipse TE2000U photomicroscope with epifluorescent capabilities connected to a digital camera (Spot RT KE). 
Table 1. Primary antibodies used in this study.

\begin{tabular}{lcccc}
\hline Antibody & Dilution & Source & Catalog number & Technique \\
\hline Aquaporin-4 & $1: 100$ & Santa Cruz & Sc-20812 & IF \\
$\beta$-catenin & $1: 500$ & Santa Cruz & sc-7963 & WB \\
Catalase (CAT) & $1: 400$ & Santa Cruz & sc-271242 & WB \\
Claudin-5 & $1: 100$ & Invitrogen & $35-2500$ & IF \\
Connexin-43 (Cx43) & $1: 500$ & Santa Cruz & sc-9059 & WB \\
GFAP & $1: 500$ & Dako & Z0334 & WB \\
GFAP & $1: 500$ & Dako & Z0334 & IHC \\
GFAP & $1: 10000$ & Sigma Aldrich & G3893 & IF \\
Laminin & $1: 500$ & Sigma Aldrich & L9393 & WB \\
Occludin & $1: 500$ & Santa Cruz & sc-5562 & WB \\
Occludin & $1: 100$ & Invitrogen & $71-1500$ & IF \\
Superoxide dismutase-1 (SOD-1) & $1: 500$ & Santa Cruz & sc-11407 & WB \\
$\beta$-actin & $1: 1000$ & Sigma Aldrich & A2228 & WB \\
\hline IF: Immunfluon & & &
\end{tabular}

IF: Immunofluorescence; IHC: Immunohistochemistry; WB: Western blotting.

2.6 ROS measurements. Cells were treated in 96-well plates for $3 \mathrm{~h} 30 \mathrm{~min}$ (RBECs) and $24 \mathrm{~h}$ (Astrocytes), washed with Ringer-HEPES and incubated for $1 \mathrm{~h}$ in RingerHEPES containing $2 \mu \mathrm{M} \quad \mathrm{CM}-\mathrm{H}_{2}$ DCFDA (Molecular Probes/Thermo Fisher Scientific) and $25 \mu \mathrm{g} / \mathrm{ml}$ Pluronic F-. CM- $\mathrm{H}_{2}$ DCFDA passively diffuses into cells, where it is modified by intracellular esterases and thiols while subsequent oxidation results in a fluorescent product. Fluorescence was monitored using a FLUOstar Optima microplate reader equipped with a 492/520 nm excitation/emission filter set.

2.7 Animal care and rGO-PEG systemic administration. All in vivo experiments were carried out at State University of Campinas and approved by the institutional Committee for Ethics in Animal Use (protocol no. 2884-1) and followed the Brazilian 
Society of Laboratory Animal Science guidelines. Male Wistar rats (Rattus norvegicus, 6-week-old, $180 \pm 40 \mathrm{~g})$ received a single i.v. injection of rGO-PEG (7 mg/kg; concentration $1 \mathrm{mg} / \mathrm{ml}$ ) [10,11], while to the control group was given the same volume of vehicle (PEG 6,000). For the sake of comparison, we treated the cells with an aqueous suspension of $\mathrm{rGO}$ and its vehicle, using the same concentrations.

All animals were euthanized by carbon dioxide $\left(\mathrm{CO}_{2}\right)$ or anesthetics overdose (3:1 mixture of ketamine chloride (Dopalen ${ }^{\circledR}, 100 \mathrm{mg} / \mathrm{kg}$ body weight,) and xylazine chloride $\left(\right.$ Anasedan $^{\circledR}, 10 \mathrm{mg} / \mathrm{kg}$ body weight, Fortvale, Valinhos, SP, Brazil) $15 \mathrm{~min}, 1$ h, $3 \mathrm{~h}$ and 7 days after the i.v. administration of rGO-PEG. Animals of the control group were euthanized $1 \mathrm{~h}$ later. A single control group was used as preliminary experiments showed no time difference relative to data.

2.8 Western blotting (WB). WB was performed in hippocampal homogenates $(n=5$ for each time, including a single control group killed $1 \mathrm{~h}$ after vehicle injection). Briefly, after being blocked with 5\% (v/v) skimmed milk in TBS-T $(0.1 \%$ Tris-buffered saline with $0.05 \%$ Tween $20, \mathrm{pH} 7.4$ ) for $1 \mathrm{~h}$ at room temperature; the membranes were incubated at $4^{\circ} \mathrm{C}$ overnight with primary antibody (Table 1). After washing with TBS-T, the membranes were incubated for $2 \mathrm{~h}$ at room temperature with the respective HRPlabeled secondary antibody (1:1000). Immunoreactive bands were visualized using a chemiluminescence kit (Super Signal West Pico Chemiluminescent Substrate; Pierce Biotechnology, Rockford, IL, USA) and recorded with a G:BoxiChemi camera (Syngene, Cambridge, UK). The blots were subsequently stripped and probed with anti$\beta$-actin to monitor protein loading, the efficiency of blot transfer, and nonspecific changes in protein levels. Bands intensities were quantified using ImageJ $1.45 \mathrm{~s}$ software (NIH, Bethesda, MD, USA). 
2.9 Immunohistochemistry (IHC). Paraffin-embedded brain sections of $5 \mu \mathrm{m}$ thickness were dewaxed and rehydrated, washed in $0.05 \mathrm{M}$ phosphate-buffered saline (PBS; $\mathrm{pH} 7.4$ ) and subjected to heat-mediated antigen retrieval treatment using 10 $\mathrm{mM}$ sodium citrate buffer for $30 \mathrm{~min}$. Endogenous peroxidase activity was quenched with $3 \%$ hydrogen peroxide for $20 \mathrm{~min}$ and then washed twice with PBS. Unspecific epitopes were blocked with $5 \%$ skimmed milk powder for $1 \mathrm{~h}$ following overnight incubation with GFAP in a humidified chamber at $4{ }^{\circ} \mathrm{C}$. After washing twice with PBS, the slides were incubated with the biotinylated anti-rabbit secondary antibody (EnVision_HRP link, Dako Cytomation, CA, USA) for $30 \mathrm{~min}$ at room temperature. Immunoreactivity was visualized as a brownish color after staining with a diaminobenzidine chromogenic solution (DAB+, Dako Cytomation) and nuclei were counterstained with Harry's hematoxylin; after ethanol dehydration slides were mounted in Entellan (Merck, Darmstadt, Germany). Parallel negative control was performed by replacing the primary antibody with $1 \%$ PBS-bovine serum albumin. Images were recorded by a Nikon Eclipse E800 photomicroscope connected to a digital camera (CoolSnap-Pro Color).

2.10 Evaluation of oxidative stress parameters. The blood samples were collected via cardiac puncture in serum separator gel tube $(n=3-5$ for each time, including a single control group killed $1 \mathrm{~h}$ after vehicle injection). The enzyme antioxidant systems (SOD and CAT) in the serum samples were measured using colorimetric methods. The SOD activity in serum was obtained after reaction with hypoxanthine, nitroblue tetrazolium and $0.07 \mathrm{U}$ of xanthine oxidase as described in detail before [17]. The CAT activity method was carried out based on the reaction of the enzyme with methanol and $\mathrm{H}_{2} \mathrm{O}_{2}$. 
Purpald (4-amino-3-hydrazino-5-mercapto-1,2,4-triazole) was used as chromogen and the resultant formaldehyde products were measured at $540 \mathrm{~nm}$ (adapted from [18]).

Lipid peroxidation was determined by measuring TBARS using a spectrophotometric method described by Ohkawa et al. [19] and adapted by Batista et al. [17] in which malondialdehyde and the final products of lipid peroxidation react with thiobarbituric acid, forming a pink-colored complex.

2.11 Statistical analysis. All data are expressed as mean \pm SEM. Statistically significant differences were assessed by Student's t test or One-way ANOVA followed by Tukey multiple comparison post-hoc test with a p-value $<0.05$ considered significant. Graphs were prepared with Prism software, version 5 (GraphPad Inc., La Jolla, CA, USA) and all of the data are expressed as mean \pm SEM.

\section{RESULTS AND DISCUSSION}

\subsection{Preparation and characterization of PEGylated rGO}

Table 2 summarizes the main physicochemical characteristics of the nonPEGylated and PEGylated rGO measured by DLS.

Table 2. Physicochemical characteristics of non-PEGylated and PEGylated rGO.

\begin{tabular}{lccc}
\hline \multicolumn{1}{c}{ Samples } & Size $(\mathbf{n m})$ & Zeta potential $(\mathbf{m V})$ & PDI \\
\hline Non-PEGylated rGO & $342 \pm 23.5$ & $-25 \pm 0.18$ & $0.56 \pm 0.03$ \\
PEGylated rGO & $910 \pm 32.7$ & $-4.2 \pm 3.8$ & $0.39 \pm 0.04$ \\
\hline
\end{tabular}

A comparison of zeta potential revealed that the charge associated with the nonPEG rGO had a greater negative zeta potential $(-25 \pm 0.18 \mathrm{mV})$ than the PEGylated 
rGO $(-4.2 \pm 3.8 \mathrm{mV})$. This suggests the existence of positive amino-ended branches, resulting in a lesser negative electrostatic charge for PEGylated rGO than rGO (Vila et al. 2012). The PEGylation of rGO leads to a decrease in PDI values $(0.56 \pm 0.03$ to 0.39 \pm 0.04 ), resulting in the diminished polydispersity of particles, probably due to a lower susceptibility to aggregate formation.

A significant increase in size, from $342 \pm 23.5 \mathrm{~nm}$ up to $910 \pm 32.7 \mathrm{~nm}$, was found after PEGylation. Although this increase offers evidence for the PEGylation of nanoparticles, confirmation of the attachment of PEG to rGO is essential. For this purpose, FTIR-ATR, ${ }^{13} \mathrm{C}$ NMR and TGA-DSC were carried out. As shown in Figure 1A, the PEGylated rGO spectrum exhibited characteristic bands at $1080 \mathrm{~cm}^{-1}$ (-C-O-C stretching), $1641 \mathrm{~cm}^{-1}(\mathrm{C}=\mathrm{O}$ stretching $)$ and $3359 \mathrm{~cm}^{-1}(\mathrm{O}-\mathrm{H}$ stretching), indicating cross-linking between PEG and rGO [20]. According to the TGA-DSC measurement results, the ratio of grafted PEG was estimated to be $78.85 \%$ (Fig. 1B). The 13C NMR spectrum of rGO exhibited a peak at 100 ppm (Fig. 1C) while rGO-PEG exhibited a peak at $70 \mathrm{ppm}$ (Fig. 1D). All ethylene glycol carbons have approximately the same microenvironment, and are thus expected to have similar chemical shift values at around 70 ppm corresponding to $-\mathrm{O}-\mathrm{CH}_{2}$ group of PEG [21].

The morphology and structure of rGO-PEG analyzed by FE-SEM and HRTEM also showed wrinkles, lateral corrugations and a scrolled appearance of rGO-PEG (Figure 1C, D). The surface morphology and structural parameters of non-PEGylated rGO have been previously demonstrated $[10,11]$.

\subsection{PEGylation of rGO increased its toxicity in astrocytes and RBECs}

We began by investigating the effects of rGO-PEG exposure on the viability of primary rat astrocytes and RBECs using EZ4U assay and the xCELLigence system. 
This system measures electrical impedance across the cell monolayer using a highdensity electrode array that coats the bottom of the well, and converts the impedance values to a Cell Index. These cell index values directly correspond to the change in the viability status of the cell [22].

The viability of astrocytes was assessed after exposure to culture medium for 24 h (negative control), rGO-PEG or vehicle (PEG), at concentrations of $10 \mu \mathrm{g} / \mathrm{ml}$ and 100 $\mu \mathrm{g} / \mathrm{ml}$. For the sake of comparison, we treated the cells with an aqueous suspension of rGO and its vehicle, using the same concentrations as the other treatments.

As shown in Figure 2, both vehicles (sterile distilled water and PEG) had no toxic effect on astrocytes, whereas PEG $(100 \mu \mathrm{g} / \mathrm{ml})$ induced a significant increase in cell viability compared to all the other groups $(\mathrm{p}<0.001)$. No substantial differences were observed between controls and cells treated with non-PEGylated rGO. Surprisingly, the viability of astrocytes decreased from $126 \%$ to $16 \%(p<0.001)$ when the astrocytes were treated with $100 \mu \mathrm{g} / \mathrm{ml}$ of rGO-PEG (Figure $2 \mathrm{~A}$ ).

Similar dose-dependent toxic effects of rGO, dispersed with PEG, Pluronic P123 or sodium deoxycholate (DOC), were reported by Wojtoniszak et al. [23]. These studies were carried out using L929 mouse fibroblasts and rGO concentrations ranging from 3.125 to $100 \mu \mathrm{g} / \mathrm{ml}$. The authors found that rGO-PEG exhibited the greatest biocompatibility with respect to Pluronic P123 and DOC. Cells exposed to the suspension of rGO-PEG at concentrations between $3.125 \mu \mathrm{g} / \mathrm{mL}$ and $25 \mu \mathrm{g} / \mathrm{mL}$ displayed relatively high viability; however, when the concentration exceeded $25 \mu \mathrm{g} / \mathrm{mL}$, viability was abruptly reduced.

In another work, Vila et al. [24] conducted a comparative study of how the number of branches of the PEG molecule affects the cellular uptake and cytotoxicity of GO. The cellular uptake of linear PEGylated GO (sized $95 \mathrm{~nm}$ ) was significantly higher 
than that of branched PEGylated GO (sized $190 \mathrm{~nm}$ ) in osteoblasts, fibroblasts and macrophages. Moreover, branched PEG $(75 \mu \mathrm{g} / \mathrm{mL})$ induced more changes in cellular function than its linear counterpart.

All experiments using xCELLigence were performed using only the highest concentration $(100 \mu \mathrm{g} / \mathrm{ml})$ of $\mathrm{rGO}$ and $\mathrm{rGO}-\mathrm{PEG}$, which was responsible for the reduction in astrocyte viability. The xCELLigence system with real-time technology allows us to dynamically observe the decrease of the cell index curve.

Very similar toxicity patterns were observed for the PEGylated rGO-treated cells using both techniques. Although alterations in the viability of astrocytes treated with non-PEGylated rGO were not found using EZ4U assay (Figure 2A), the cell index of rGO-treated cells was lower than the control vehicle (Figure 2B). This may be the result of minor morphological changes in the cells affecting the cell index [25].

Immunostaining of the astrocytic markers GFAP and Aquaporin-4 was used to analyze morphological alterations in the astrocytes exposed for $24 \mathrm{~h}$ to non-PEGylated and PEGylated-rGO. Immunostaining resulted in clear immunoreactivity for both proteins, with an almost total overlap. When compared to the control cells (Figure 2C, F), both rGO and rGO-PEG produced morphological changes in the rat astrocytes. Astrocytes treated with rGO presented moderate body and process retraction (Figure 2D, G), while astrocytes treated with rGO-PEG exhibited a complete absence of normal cell structure, the loss of cell-to-cell contact, and a noticeable reduction in the number of astrocytes (Figure 2E, H).

The cultured astrocytes presented atrophy and cell death after $24 \mathrm{~h}$ of exposure to PEGylated rGO. It is well known that CNS injury activates astrocytes in a process known as reactive gliosis or astrogliosis, which is manifested through astrocyte hyperplasia or hypertrophy of cell processes caused by variable up-regulation of 
cytoskeletal-forming GFAP [26]. However, Zhao et al. [27] have reported that damage to or death of astrocytes can occur in the early periods after brain injury, with concomitant down-regulation of GFAP immunoreactivity, which can be followed in later periods by reactive GFAP upregulation and the formation of glia scars to protect the injured region of the brain.

As rGO-PEG displayed cytotoxic effects on astrocytes, we subsequently assessed the impact of rGO-PEG upon RBECs with BBB phenotype. After $24 \mathrm{~h}$ of incubation with supplements which enhanced the BBB phenotype, once the growth of the RBECs reached a steady plateau, we began treatment with nanomaterials. As the brain endothelial cells are more sensitive to injury than astrocytes, the viability of the RBECs was assessed after exposure to treatments for $3 \mathrm{~h} 30 \mathrm{~min}$.

As for the astrocytes, no substantial differences were observed in cells treated with non-PEGylated rGO. The $10 \mu \mathrm{g} / \mathrm{ml}$ and $100 \mu \mathrm{g} / \mathrm{ml}$ PEG groups had significantly higher levels than all the other groups $(\mathrm{p}<0.001)$. Cell viability also decreased in RBECs incubated with $100 \mu \mathrm{g} / \mathrm{ml}$ of rGO-PEG $(\mathrm{p}<0.001)$ (Figure $3 \mathrm{~A})$.

Cell index values were monitored continuously for $24 \mathrm{~h}$. While rGO induced a slight decrease in the cell index, rGO-PEG treatment led to a rapid reduction within $5 \mathrm{~h}$. This drop was much more pronounced than that seen in astrocytes in response to similar treatment. This suggests that astrocytes are more resistant to toxic insult than endothelial cells. This finding is in line with earlier results showing that cerebral endothelial cells had a higher susceptibility to oxidative stress than astrocytes [28]. PEG alone did not affect the cell index during long-term treatment (Figure 3A), indicating that the polymer has no damaging effects on RBECs. In some cases, PEG by itself can even enhance the properties of the endothelial barrier [29]. 
Immunofluorescent studies using antibodies directed against junctional proteins shed light on the molecular background of decreased functionality of the cerebral endothelium in response to rGO-PEG treatment. Under control conditions, fine, continuous membrane staining was observed (Figure 3C, E). However, the expression patterns of the $\mathrm{TJ}$ proteins were significantly altered in the $\mathrm{rGO}$ - and $\mathrm{rGO}$ PEG-treated groups. The rGO group showed irregular and discontinuous expression of occludin and claudin 5 (Figure 3D, inset), while rGO-PEG induced widespread disruption of the RBEC monolayer, which is indicative of cell-cell junction damage (Figure 3F).

Occludin and claudins are transmembrane proteins of the tight junctions, and control paracellular permeability. In cerebral endothelial cells claudin-5 plays a more important role, with a lack of this protein leading to the opening of the BBB for substances with a molecular weight of less than 800 Da [30]. Our results indicate that rGO-PEG has a barrier damaging effect when used in high concentrations.

\section{3 rGO-PEG induced BBB breakdown and in vivo astrocyte dysfunction}

While in vitro models are practical and cost-effective methods for screening the toxicity of potential drug carriers, they cannot completely replace the complexity of animal and human responses. Therefore, the following step was carried out to investigate the in vivo effects of rGO-PEG.

We had previously detected the presence of rGO inside the thalamus and hippocampus by matrix-assisted laser desorption/ionization (MALDI) mass spectrometry imaging (MSI). We also found that intravenous (i.v.) injection of rGO induced a transient blood-brain barrier opening in the hippocampus. We found downregulation of junctional proteins (the tight junction protein occluding and the 
adherens junction protein $\beta$-catenin) and laminin. When taken together, these are coresponsible for maintaining the paracellular tightness of the BBB [10]. In the present study, we used the same rat model and experimental design to evaluate the expression of these three BBB-associated proteins in the rat hippocampus after rGO-PEG i.v. administration.

The rGO-PEG caused a significant decrease in occludin $(32 \%, \mathrm{p}<0.01), \beta$ catenin $(85 \%, \mathrm{p}<0.001)$ and laminin $(134 \%, \mathrm{p}<0.01)$ levels $3 \mathrm{~h}$ after administration. This did not increase thereafter; instead, by day 7, the proteins had reached their highest level of down-regulation $(\mathrm{p}<0.001)$ (Figure 4).

The significant and long-lasting downregulation of BBB-associated proteins induced by PEGylated rGO implies impaired BBB function and probably a homeostatic disturbance of the hippocampal milieu. In contrast, non-PEGylated rGO induced a transient and slighter down-regulation of BBB-associated proteins which was resolved seven days post-rGO exposure [10], an indication that rGO is more qualified than GOPEG in terms of being explored in the field of neuroscience research.

Analysis of hippocampal homogenates from non-PEGylated rGO-treated rats did not show significant changes in the levels of GFAP (Figure 5A) and Cx43 (Figure 5B). Unexpectedly, the stimulus generated by rGO-PEG did not increase the expression of GFAP, either acutely or in late periods following administration. Instead, it induced a decrease in the expression of GFAP at $3 \mathrm{~h}(47 \%, \mathrm{p}<0.05)$ and 7 days $(95 \%, \mathrm{p}<0.001)$ post-rGO-PEG injection (Figure 5A), in comparison with the control vehicle. An explanation for this data is given by the findings obtained for in vitro-cultured astrocytes, which unarguably demonstrated a significant decrease in astrocyte viability through EZ4U assay and xCELLigence. Immunohistochemical analysis of GFAPpositive cells in the hippocampus (Fig. $5 \mathrm{C}$-E) corroborated the in vitro data. Therefore, 
we can state that the decrease of GFAP expression in the hippocampus of rats i.v. injected with rGO-PEG, but not with non-PEGylated rGO, was due to the death of a number of astrocytes.

Similarly to GFAP, the i.v. injection of rGO-PEG led to a reduction in $\mathrm{Cx} 43$ expression at $3 \mathrm{~h}$ and 7 days $(159 \%, \mathrm{p}<0.001)$ (Figure $5 \mathrm{~B})$ when compared to the control vehicle. These findings offer a plausible hypothesis that the strong retraction of the astrocyte processes and a loss of viability (seen in in vitro preparations) most likely eliminated homotypic contacts among the astrocyte processes, and even heterotypic contacts among astrocytes and endothelial cells and/or neuronal cells, also in vivo. Therefore, we suggest that the long-lasting and progressive decrease of $\mathrm{Cx} 43$ from $3 \mathrm{~h}$ to 7 days following the systemic administration of rGO-PEG, but not after the administration of non-PEGylated rGO, impaired the exchange of information among astrocytes due to non-operant GJs.

Astrocytes are key regulators of BBB integrity and have an impressive capacity to modulate CNS homeostasis [31]. Typically, under stimuli, the astrocytes react by proliferation or the hypertrophy of cytoplasmic processes and increased expression of the intermediate filament protein GFAP from astrocyte cytoskeleton. They are also able to increase or decrease the expression of the gap-junction (GJ) protein connexin-43 (Cx43) depending on the stimulus, thus regulating the exchange of information between cells. Changes in the expression of $\mathrm{Cx} 43$ and the exchange of information among astrocytes are relevant to many brain lesions and pathologies [32], as they can result in the dissemination of the pathological state and/or the accumulation of toxicants in the absence of functional GJ channels [33]. 
A recent study reported that the lack of $\mathrm{Cx} 43$ expression or the blockade of Cx43 channels results in increased reactive oxygen species (ROS)-induced astrocytic death [34], one of the several mechanisms leading to nanotoxicity [35].

\subsection{PEGylation of rGO increased ROS generation}

To further widen our understanding of the mechanisms triggering toxicity we investigated if rGO-PEG treatment affects ROS generation (in vitro) and the antioxidant enzymatic system (in vivo) in comparison with the effect of non-PEGylated rGO.

Measurement of ROS formation was performed using an oxidant-sensitive fluorogenic probe CM-H2DCFDA (5-(6)-chloromethyl-2',7'-dichlorodihydrofluorescein diacetate, acetyl ester). An increase in CM-H2DCFDA fluorescence reflects an increase in ROS levels [36].

Following a $24 \mathrm{~h}$ exposure of astrocytes to nanomaterials, intracellular ROS levels significantly increased in both PEGylated and non-PEGylated rGO-treated cells (Figure 6A). The highest concentration of rGO-PEG induced a $270 \%$ increase in the intracellular levels of ROS $(p<0.001)$, while rGO induced a $33 \%$ increase $(p<0.001)$, in comparison with their respective vehicle controls.

The non-PEGylated rGO did not induce ROS production in RBECs, but as with the astrocytes response, the highest concentration $(100 \mu \mathrm{g} / \mathrm{ml})$ of rGO-PEG enhanced the generation of ROS $(\mathrm{p}<0.001)$ in RBECs, in comparison with all other groups (Figure $6 B)$.

This data supports our hypothesis that oxidative stress is a major factor in the toxicity of rGO-PEG. The induction of ROS generation seems to be a general cellular response to rGO-PEG. Reshma et al. [37] described the production of ROS in A549 cells after treatment with PEGylated rGO and non-PEGylated rGO. Their results reveal 
that PEGylated rGO were able to induce prominent ROS production at all time-points $(0.5,2,4,5$ and $24 \mathrm{~h})$ and at concentrations ranging from 5 to $100 \mu \mathrm{g} / \mathrm{ml}$. The authors found that $\mathrm{rGO}$ failed to generate $\mathrm{ROS}$ at up to $4 \mathrm{~h}$ as the concentration of the particle increased from 5 to $100 \mu \mathrm{g} / \mathrm{ml}$. However, ROS generation increased after $6 \mathrm{~h}$ of exposure to $50 \mu \mathrm{g} / \mathrm{ml}$ and after 6 and $24 \mathrm{~h}$ of exposure to $100 \mu \mathrm{g} / \mathrm{ml}$. The findings show that the formation of ROS depends of variables such as time of exposure and the concentration of the nanoparticle, which may suggest that antioxidant activity is likely to depend on the same variables.

The detoxification of excess ROS is mediated by an efficient antioxidant system comprising non-enzymatic molecules and antioxidant enzymes [38], the most efficient of which are enzymatic antioxidants glutathione peroxidase, catalase and superoxide dismutase (SOD) [39].

We initiated our in vivo analysis by evaluating the protein expression of catalase and SOD-1 in the hippocampus. As shown in Figure 7, the expression of catalase was $27 \%$ higher at $3 \mathrm{~h}(\mathrm{p}<0.01)$ and $18 \%$ higher at 7 days $(\mathrm{p}<0.05)$ post-rGO-PEG administration, in comparison with control levels. Interestingly, only a $12 \%$ increase was detected in SOD-1 expression by day 7 (Figure 7B).

To determine whether the protein levels of catalase and SOD-1 in hippocampus paralleled the activity level of the enzymes, we measured total SODs and catalase activities from serum samples. Over time, increases in the antioxidant enzymes and in lipid peroxidation measured by thiobarbituric acid reactive substances (TBARS) were observed (Table 3).

SOD catalyzes the conversion of superoxide anions to oxygen and hydrogen peroxide. Thus, CAT converts hydrogen peroxide to water and oxygen and completes the detoxification initiated by SOD [39]. It has been found that cells can tolerate 
moderate oxidative stress by up-regulating their reductive defense systems and restoring the oxidant/antioxidant balance [40]. Taken together, these results indicate that the increase in catalase and SOD activity/expression could be due to oxidative stress generation and may suggest a possible adaptive mechanism against insults caused by rGO-PEG administration.

Table 3. Serum levels of SOD, catalase and TBARS after rGO-PEG treatment.

\begin{tabular}{|c|c|c|c|c|c|c|}
\hline & Unit & Control & $\begin{array}{c}\text { rGO-PEG } \\
15 \mathrm{~min}\end{array}$ & $\begin{array}{c}\text { rGO-PEG } \\
1 \mathrm{~h}\end{array}$ & $\begin{array}{c}\text { rGO-PEG } \\
3 \mathrm{~h}\end{array}$ & $\begin{array}{c}\text { rGO-PEG } \\
7 \mathrm{~d}\end{array}$ \\
\hline CAT & $\mathrm{nmol} / \mathrm{min} / \mathrm{ml}$ & $64 \pm 14.6$ & $71 \pm 12.8$ & $88 \pm 19.8$ & $89 \pm 9.4$ & $123 \pm 18.3^{*}$ \\
\hline SOD & $\mathrm{U} / \mathrm{ml}$ & $35 \pm 2.2$ & $56 \pm 7.8$ & $43 \pm 0.5^{*}$ & $49 \pm 2.4^{* *}$ & $49 \pm 3.9^{*}$ \\
\hline TBARS & $\mathrm{nmol} / \mathrm{ml}$ & $3.0 \pm 0.8$ & $2.9 \pm 0.7$ & $3.4 \pm 0.5$ & $3.5 \pm 0.2$ & $4.4 \pm 0.7$ \\
\hline
\end{tabular}

\section{CONCLUSIONS}

The PEGylation of nanomaterials and therapeutics is currently considered to be one of the most promising approaches to reducing toxicity and obtaining favorable pharmacokinetic results. However, deleterious effects and death have been observed in different cell types treated with PEGylated nanoparticles, mostly through the induction of oxidative stress, which corroborated the results of the present experimental design.

Herein, the combined in vitro and in vivo toxicity profiles of PEGylated rGO have been investigated and reported for the first time. The data of the present study suggest the dose- and time-dependent toxicity of PEGylated rGO for key components of the blood-brain barrier, such as astrocytes and endothelial cells. In terms of toxicity mechanisms, the formation of intracellular ROS and the increase in the enzymatic 
antioxidant system induced by PEGylated-rGO suggest oxidative stress-mediated damage.

\section{ACKNOWLEDGMENTS}

This work is supported by the Brazilian funding agencies, Fundação de Amparo à Pesquisa do Estado de São Paulo (FAPESP) (MCPM's doctorat studentships nos. 2012/24782-5 and 2015/03254-9), Conselho Nacional de Desenvolvimento Científico e Tecnológico (CNPq) (grant no. 305099/2011-6) and Coordenação de Aperfeiçoamento de Pessoal de Nível Superior (CAPES). We dedicate this study to Professor Vitor Baranauskas (Brazilian Academy of Sciences, in memoriam) by his contribution to science in the last years.

\section{REFERENCES}

1. Zhang, Y.; Nayak, T.R.; Hong, H.; Cai, W. Graphene: a versatile nanoplatform for biomedical applications. Nanoscale. 2012, 4 (13), 3833-3842.

2. Byun, J. Emerging frontiers of graphene in biomedicine. $J$ Microbiol Biotechnol. 2015, 25 (2), 145-151.

3. John, A.A.; Subramanian, A.P.; Vellayappan, M.V.; Balaji, A.; Mohandas, H.; Jaganathan, S.K. Carbon nanotubes and graphene as emerging candidates in neuroregeneration and neurodrug delivery. Int J Nanomedicine. 2015, 10, 42674277.

4. Guo, W.; Wang, S.; Yu, X.; Qiu, J.; Li, J.; Tang, W.; Li, Z.; Mou, X.; Liu, H.; Wang, Z. Construction of a 3D rGO-collagen hybrid scaffold for enhancement of the neural differentiation of mesenchymal stem cells. Nanoscale. 2016, 8, 18971904. 
5. Bottini, M.; Rosato, N.; Bottini, N.; Huang, X.; Teng, X.; Chen, D.; Tang, F.; He, J. PEG-modified nanotubes in biomedicine: current status and challenges ahead. Biomacromolecules. 2011, 12, 3381-3393.

6. Jokerst, J.V.; Lobovkina, T.; Zare, R.N.; Gambhir, S.S. Nanoparticle PEGylation for imaging and therapy. Nanomedicine (Lond). 2011, 6 (4), 715-278.

7. Verhoef, J.J.; Anchordoquy, T.J. Questioning the use of PEGylation for drug delivery. Drug Deliv Transl Res. 2013, 3 (6), 499-503.

8. Soenen, S.J.; Manshian, B.B.; Abdelmonem, A.M.; Montenegro, J-M.; Tan, S.; Balcaen, L.; Vanhaecke, F.; Brisson, A.R.; Parak, W.J.; Smedt, S.C.D.; Braeckmans, K. The cellular interactions of PEGylated gold nanoparticles: effect of PEGylation on cellular uptake and cytotoxicity. Part Part Syst Charact. 2014, 31, $794-800$.

9. Moret, F.; Selvestrel, F.; Lubian, E.; Mognato, M.; Celotti, L.; Mancin, F.; Reddi, E. PEGylation of ORMOSIL nanoparticles differently modulates the in vitro toxicity toward human lung cells. Arch Toxicol. 2015, 89 (4), 607-620.

10. Mendonça, M.C.; Soares, E.S.; de Jesus, M.B.; Ceragioli, H.J.; Ferreira, M.S.; Catharino, R.R.; da Cruz-Höfling, M.A. Reduced graphene oxide induces transient blood-brain barrier opening: an in vivo study. J Nanobiotechnol. 2015, 13, 78, DOI: $10.1186 / \mathrm{s} 12951-015-0143-\mathrm{Z}$

11. Mendonça, M.C.; Soares, E.S.; de Jesus, M.B.; Ceragioli, H.J.; Irazusta, S.P.; Batista, Â.G.; Vinolo, M.A.; Maróstica Júnior, M.R.; da Cruz-Höfling, M.A. Reduced graphene oxide: nanotoxicological profile in rats. J Nanobiotechnol. 2016, 14 (1), 53, DOI: 10.1186/s12951-016-0206-9

12. Hawkins, B.T.; Davis, T.P. The blood-brain barrier/neurovascular unit in health and disease. Pharmacol Rev. 2005, 57 (2), 173-185. 
13. Luissint, A.C. Artus, C.; Glacial, F.; Ganeshamoorthy, K.; Couraud, P.O. Tight junctions at the blood brain barrier: physiological architecture and diseaseassociated dysregulation. Fluids Barriers CNS. 2012, 9 (1), 23, DOI: doi: 10.1186/2045-8118-9-23

14. Wilhelm, I.; Fazakas, C.; Krizbai, I.A. In vitro models of the blood-brain barrier. Acta Neurobiol Exp. 2011, 71, 113-128.

15. Lindstrom, N.M.; Moore, D.M.; Zimmerman, K.; Smith, S.A. Hematologic assessment in pet rats, mice, hamsters, and gerbils: blood sample collection and blood cell identification. Vet Clin North Am Exot Anim Pract. 2015, 18 (1), 21-32.

16. Guo, X.; Mei, N. Assessment of the toxic potential of graphene family nanomaterials. J Food Drug Anal. 2014, 22 (1), 105-115.

17. Batista, A.G.; Lenquiste, S.A.; Cazarin, C.B.B.; da Silva, J.K.; Luiz-Ferreira, A.; Bogusz Junior. S.; Hantao, L.W.; de Souza, R.N.; Augusto, F.; Prado, M.A.; Maróstica Junior, M.R. Intake of jaboticaba peel attenuates oxidative stress in tissues and reduces circulating saturated lipids of rats with high-fat diet-induced obesity. J Funct Foods. 2014, 6, 450-461.

18. Johansson, L.H.; Borg, L.A.H. A spectrophotometric method for determination of catalase activity in small tissue samples. Anal Biochem. 1988, 174, 331-336.

19. Ohkawa, H.; Ohishi, N.; Yagi, K. Assay for lipid peroxides in animal-tissues by thiobarbituric acid reaction. Anal Biochem.1979, 95, 351-358.

20. Gupta, B.; Kumar, N.; Panda, K.; Dash, S.; Tyagi, A.K. Energy efficient reduced graphene oxide additives: mechanism of effective lubrication and antiwear properties. Sci. Rep. 2016, 6, 18372, DOI: 10.1038/srep18372 
21. Zinkevich, T.; Venderbosch, B.; Jaspers, M.; Kouwer, P.H.; Rowan, A.E.; van Eck, E.R.; Kentgens, A.P. Solid-state NMR characterization of tri-ethyleneglycol grafted polyisocyanopeptides. Magn Reson Chem. 2016, 54 (4), 328-333.

22. Ke, N.; Wang, X.; Xu, X.; Abassi, Y.A. The xCELLigence system for real-time and label-free monitoring of cell viability. Methods Mol Biol. 2011, 740, 33-43.

23. Wojtoniszak, M.; Chen, X.; Kalenczuk, R.J.; Wajda, A.; Łapczuk, J.; Kurzewski, M.; Drozdzik, M.; Chu, P.K.; Borowiak-Palen, E. Synthesis, dispersion, and cytocompatibility of graphene oxide and reduced graphene oxide. Colloids Surf B Biointerfaces. 2012, 89, 79-85.

24. Vila. M.; Portolés, M.T.; Marques, P.A.; Feito, M.J.; Matesanz, M.C.; RamírezSantillán, C.; Gonçalves, G.; Cruz, S.M.; Nieto, A.; Vallet-Regi, M. Cell uptake survey of pegylated nanographene oxide. Nanotechnology. 2012, 23 (46), 465103, DOI: $10.1088 / 0957-4484 / 23 / 46 / 465103$

25. Kho, D.; MacDonald, C.; Johnson, R.; Unsworth, C.P.; O'Carroll, S.J.; Mez, E.D.; Angel, C.E.; Graham, E.S. Application of xCELLigence RTCA Biosensor Technology for Revealing the Profile and Window of Drug Responsiveness in Real Time. Biosensors. 2015, 5, 199-222.

26. Sofroniew, M.V.; Vinters, H.V. Astrocytes: biology and pathology. Acta Neuropathol. 2010, 119 (1), 7-35.

27. Zhao, X.; Ahram, A.; Berman, R.F.; Muizelaar, J.P.; Lyeth, B.G. Early loss of astrocytes after experimental traumatic brain injury. Glia. 2003, 44 (2), 140-152.

28. Bresgen, N.; Jaksch, H.; Bauer, H.C.; Eckl, P.; Krizbai, I.; Tempfer, H. Astrocytes are more resistant than cerebral endothelial cells toward geno- and cytotoxicity mediated by short-term oxidative stress. J Neurosci Res. 2006, 84 (8), 1821-1828. 
29. Chiang, E.T.; Camp, S.M.; Dudek, S.M.; Brown, M.E.; Usatyuk, P.V.; Zaborina, O.; Alverdy, J.C.; Garcia, J.G. Protective effects of high-molecular weight polyethylene glycol (PEG) in human lung endothelial cell barrier regulation: role of actin cytoskeletal rearrangement. Microvasc Res. 2009, 77 (2), 174-186.

30. Nitta, T.; Hata, M.; Gotoh, S.; Seo, Y.; Sasaki, H.; Hashimoto, N.; Furuse, M.; Tsukita, S. Size-selective loosening of the blood-brain barrier in claudin-5-deficient mice. J Cell Biol. 2003, 161 (3), 653-660.

31. Verkhratsky, A.; Nedergaard, M. Astroglial cradle in the life of the synapse. Phil. Trans. R. Soc. Lond. B. Biol. Sci. 2014, 369, 20130595, DOI: $10.1098 /$ rstb.2013.0595.

32. Rouach, N.; Avignone, E.; Même, W.; Koulakoff, A.; Venance, L.; Blomstrand, F.; Giaume, C. Gap junction and connexin expression in the normal and pathological central nervous system. Biol Cell. 2002, 94 (7-8), 457-475.

33. Wallraff, A.; Kohling, R.; Heinemann, U.; Theis, M.; Willecke, K.; Steinhauser, C. The impact of astrocytic junctional coupling on potassium buffering in the hippocampus. J. Neurosci. 2006, 26, 5438-5447.

34. Le, H.T.; Sin, W.C.; Lozinsky, S.; Bechberger, J.; Vega, J.L.; Guo, X.Q.; Sáez, J.C.; Naus, C.C. Gap junction intercellular communication mediated by connexin 43 in astrocytes is essential for their resistance to oxidative stress. $J$ Biol Chem. 2014, 289 (3), 1345-1354.

35. de Jesus, M.B.; Kapila, Y.L. Cellular mechanisms in nanomaterial internalization, intracellular trafficking, and toxicity. In Nanomedicine and Nanotoxicology, 1st ed.; Durán, N., Guterres, S.S, Alves, O.L., Eds.; Springer: New York, 2014; pp. 201-27. 
36. Karlsson, M.; Kurz, T.; Brunk, U.T.; Nilsson, S.E.; Frennesson, C.I. What does the commonly used DCF test for oxidative stress really show? Biochem J. 2010, 428 (2), 183-190.

37. Reshma, S.C.; Syama, S.; Mohanan, P.V. Nano-biointeractions of PEGylated and bare reduced graphene oxide on lung alveolar epithelial cells: A comparative in vitro study. Colloids Surf B Biointerfaces. 2015, 140, 104-116.

38. Liou, G.Y.; Storz, P. Reactive oxygen species in cancer. Free Radic Res. 2010, 44 (5), 479-496.

39. Rahman, K. Studies on free radicals, antioxidants, and co-factors. Clin Interv Aging. 2007, 2 (2), 219-236.

40. Halliwell, B. Free radicals and other reactive species in disease. John Wiley and Sons. 2015, DOI: 10.1002/9780470015902.a0002269.pub3

\section{Figure legends}

Figure 1. rGO-PEG characterization. (A) Fourier-transform infrared spectroscopy in the attenuated total reflectance mode (FTIR-ATR); (B) TGA curves of rGO-PEG; 13C NMR spectra of (C) rGO and (D) rGO-PEG; (E) Representative FE-SEM and (D) HRTEM images showing part of rGO-PEG. A.u = Arbitrary units.

\section{Figure 2. Effect of rGO and rGO-PEG treatment on cultures of rat astrocytes.}

Astrocytes were incubated with different concentrations $(10 \mu \mathrm{g} / \mathrm{ml}$ and $100 \mu \mathrm{g} / \mathrm{ml})$ of (A) rGO and rGO-PEG during $24 \mathrm{~h}$. Culture medium was used as negative control. The rGO vehicle (sterile distilled water) and rGO-PEG vehicle (PEG) were used as controls. The viability of the cells was measured using EZ4U assay $24 \mathrm{~h}$ after rGO or rGO-PEG 
treatment. The percentage is given in relation to control medium and the columns are the mean \pm SEM ( $\mathrm{n}=4)$. (B) Analysis of cell viability using xCELLigence system. The curves represent the average of four individual well \pm SEM of a representative experiment. (C-H) Representative immunofluorescence images for glial fibrillary acidic protein (GFAP) (red) and Aquaporin-4 (green) after (C) sterile distilled water, (F) PEG, (D, G) rGO $100 \mu \mathrm{g} / \mathrm{ml}$, and (E, H) rGO-PEG $100 \mu \mathrm{g} / \mathrm{ml}$ treatment. Nuclei were stained with Hoechst (blue). ${ }^{* * *} \mathrm{p}<0.001 v s$. all other groups; $\phi \phi \phi \mathrm{p}<0.001$ vs. all other groups (One-way ANOVA plus Tukey post-comparison test). Bar: $100 \mu \mathrm{m}$ for all panels.

Figure 3. Effects of rGO and rGO-PEG treatment on RBECs. Analyses of cell viability using (A) EZ4U assay and (B) xCELLigence system. Culture medium was used as negative control. The rGO vehicle (sterile distilled water) and rGO-PEG vehicle (PEG) were used as blank controls. The viability of the cells was measured using EZ4U assay $3 \mathrm{~h} 30 \mathrm{~min}$ after rGO or rGO-PEG treatment. The percentage is given in relation to control medium and the columns are the mean $\pm \operatorname{SEM}(n=4)$. (B) Analysis of cell viability using $\mathrm{xCELLigence}$ system. The curves represent the average of four individual well \pm SEM of a representative experiment. (C-F) Double immunostaining for claudin-5 (red) and occludin (green) performed $5 \mathrm{~h}$ after treatment with $100 \mu \mathrm{g} / \mathrm{ml}$ of (C) sterile distilled water, (D) rGO, (E) PEG and (F) rGO-PEG. Nuclei were stained with Hoechst (blue). Asterisks show holes formed between endothelial cells. Arrows indicate fragmentation and loss of junctional immunostaining. \#p<0.05 vs. control PEG $100 \mu \mathrm{g} / \mathrm{ml} ; \# \# \# \mathrm{p}<0.001$ vs. all other groups; ${ }^{*} \mathrm{p}<0.05$ vs. control PEG 10 $\mu \mathrm{g} / \mathrm{ml} ; * * \mathrm{p}<0.001$ vs. all other groups; $\phi \phi \phi \mathrm{p}<0.001$ vs. all other groups (One-way ANOVA plus Tukey post-comparison test). Bar: $100 \mu \mathrm{m}$ for all panels. 
Figure 4. Expression of proteins associated with BBB in the hippocampus as assessed by western blotting. The panels show the expression of (A) occludin, (B) $\beta$ catenin and (C) laminin at different intervals after rGO-PEG administration $(7 \mathrm{mg} / \mathrm{kg}$, i.v.). Immunoreactive bands were quantified densitometrically and normalized to an internal standard ( $\beta$-actin). The results were shown as percentage of control $(100 \%)$, and represent mean \pm SEM $\left(\mathrm{n}=5\right.$ rats/interval). ${ }^{*} \mathrm{p}<0.05, * * \mathrm{p}<0.01$ and $* * * \mathrm{p}<0.001$ compared to the control (Student's t-test).

Figure 5. Effects of rGO-PEG treatment on astrocytic markers in vivo. Expression of (A) GFAP and (B) Cx43 at different intervals after rGO and rGO-PEG (7 mg/kg, i.v.) administration. Immunoreactive bands were quantified densitometrically and normalized to an internal standard ( $\beta$-actin). The results were shown as percentage of control $(100 \%)$, and represent mean \pm SEM $(n=5$ rats/interval). Representative images of GFAP immunostaining (brown color) in CA1 hippocampal region. (C) Control PEG, (D) $3 \mathrm{~h}$ and (E) 7 days after rGO-PEG treatment. $\mathrm{A}=\# \mathrm{p}<0.05$ vs. control $\mathrm{H}_{2} \mathrm{O}$, control PEG, rGO-PEG 1h; *p<0.05 vs. rGO 3 h, 7d; **p<0.01 vs. rGO 15 min, 1 h, rGO-PEG 15 min; ***p $<0.001$ vs. control H2O, control PEG, rGO-PEG 1 h. $\mathrm{B}=* \mathrm{p}<0.05$ vs. rGO 15 min, 3 h, 7 d, rGO-PEG 1 h; ***p<0.001 vs. control H2O, rGO 1 h, control PEG (One-way ANOVA plus Tukey post-comparison test). Bar: $50 \mu \mathrm{m}$.

Figure 6. ROS levels in astrocytes and RBECs incubated with rGO and rGO-PEG. Intracellular ROS levels were detected with $\mathrm{CM}-\mathrm{H}_{2}$-DCFDA in (A) astrocytes and (B) RBECs after $24 \mathrm{~h}$ and $3 \mathrm{~h}$ and $30 \mathrm{~min}$, respectively. The bars show the quantitative analysis of fluorescent intensity from four experiments. Data represent the mean \pm SEM. $\mathrm{A}=\phi \mathrm{p}<0.05$ vs. control PEG $10 \mu \mathrm{g} / \mathrm{ml} ; \phi \phi \mathrm{p}<0.01$ vs. control PEG $100 \mu \mathrm{g} / \mathrm{ml}$; 
\#\#\#p $<0.001$ vs. control PEG $10 \mu \mathrm{g} / \mathrm{ml}$, rGO-PEG $10 \mu \mathrm{g} / \mathrm{ml}$, control PEG $100 \mu \mathrm{g} / \mathrm{ml}$; $* * * \mathrm{p}<0.001$ vs. all other groups. $\mathrm{B}=\phi \phi \mathrm{p}<0.01$ vs. control $\mathrm{H}_{2} \mathrm{O} 10 \mu \mathrm{g} / \mathrm{ml}, 100 \mu \mathrm{g} / \mathrm{ml}$, $\# \mathrm{p}<0.05$ vs. control $\mathrm{H}_{2} \mathrm{O} 10 \mu \mathrm{g} / \mathrm{ml}, 100 \mu \mathrm{g} / \mathrm{ml} ; * * * \mathrm{p}<0.001$ vs. all other groups (Oneway ANOVA plus Tukey post-comparison test).

Figure 7. Effects of rGO-PEG administration in antioxidant enzymes. (A) Densitometric analysis of (A) catalase and (B) SOD-1 performed after normalization with $\beta$-action. The results were expressed as percentage of control $(100 \%)$ and columns represent the mean $\pm \operatorname{SEM}\left(\mathrm{n}=5\right.$ rats/interval). ${ }^{*} \mathrm{p}<0.05,{ }^{*} \mathrm{p}<0.01$ and $* * * \mathrm{p}<0.001$ compared to the control (Student's t test). 


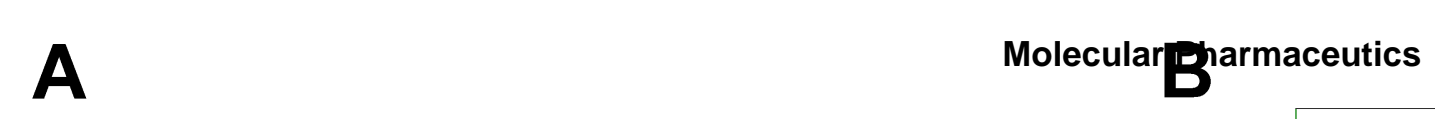

Page 32 of 39
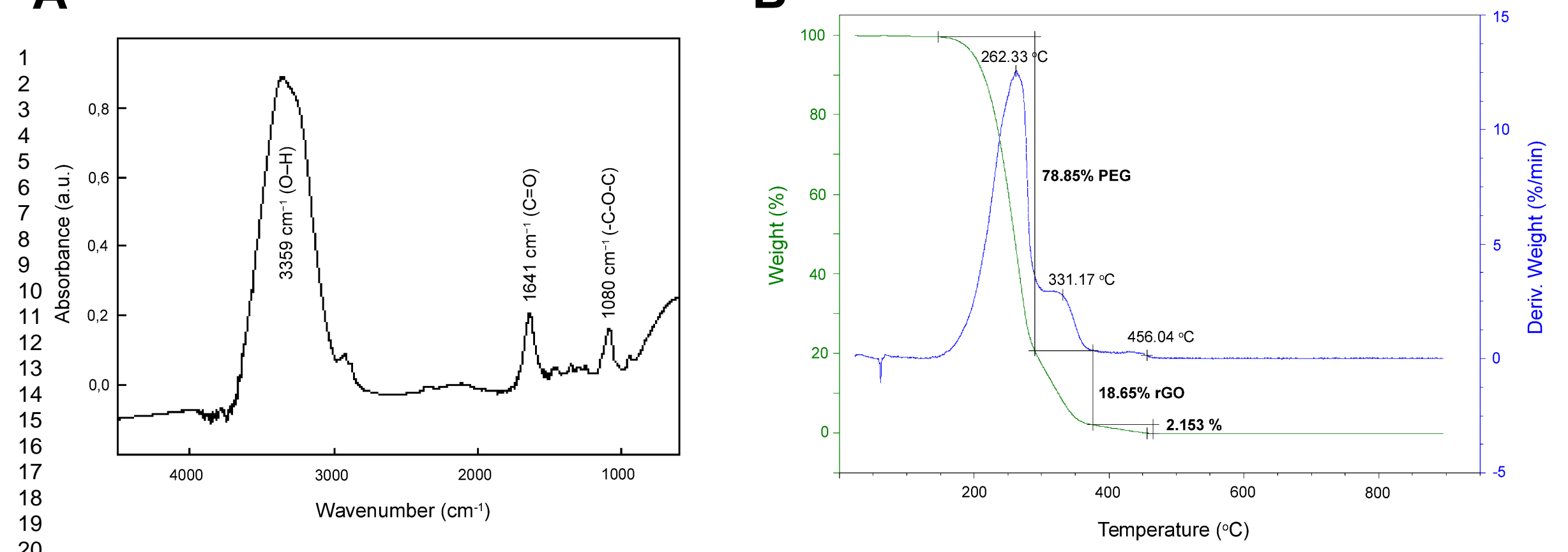

${ }_{22}^{21}$

23

24

25

26

27

28

29

30

31

32

33

34

35

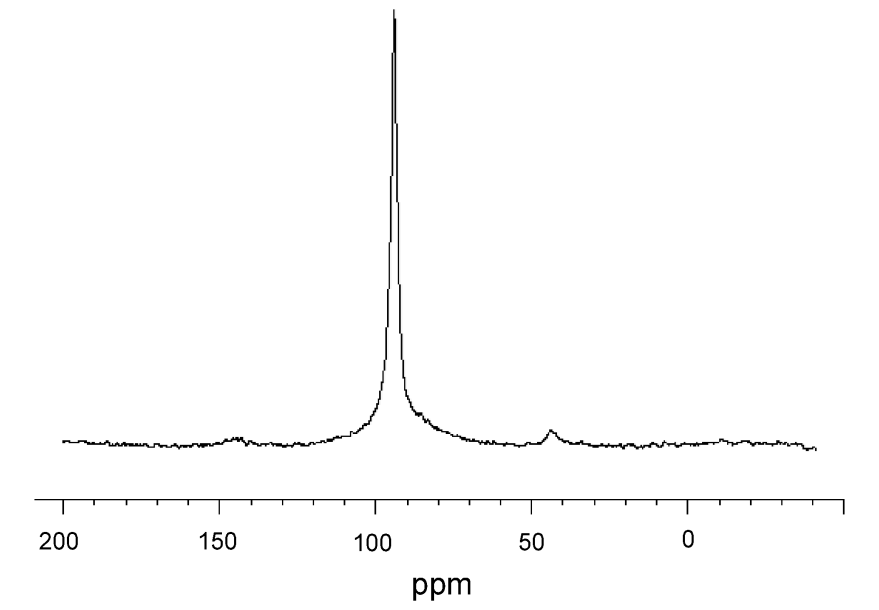

D

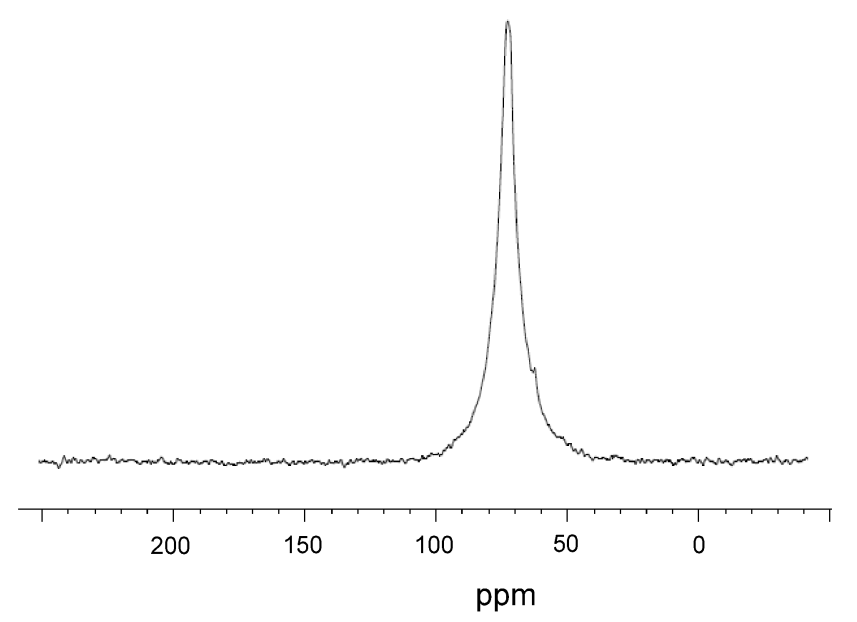

F
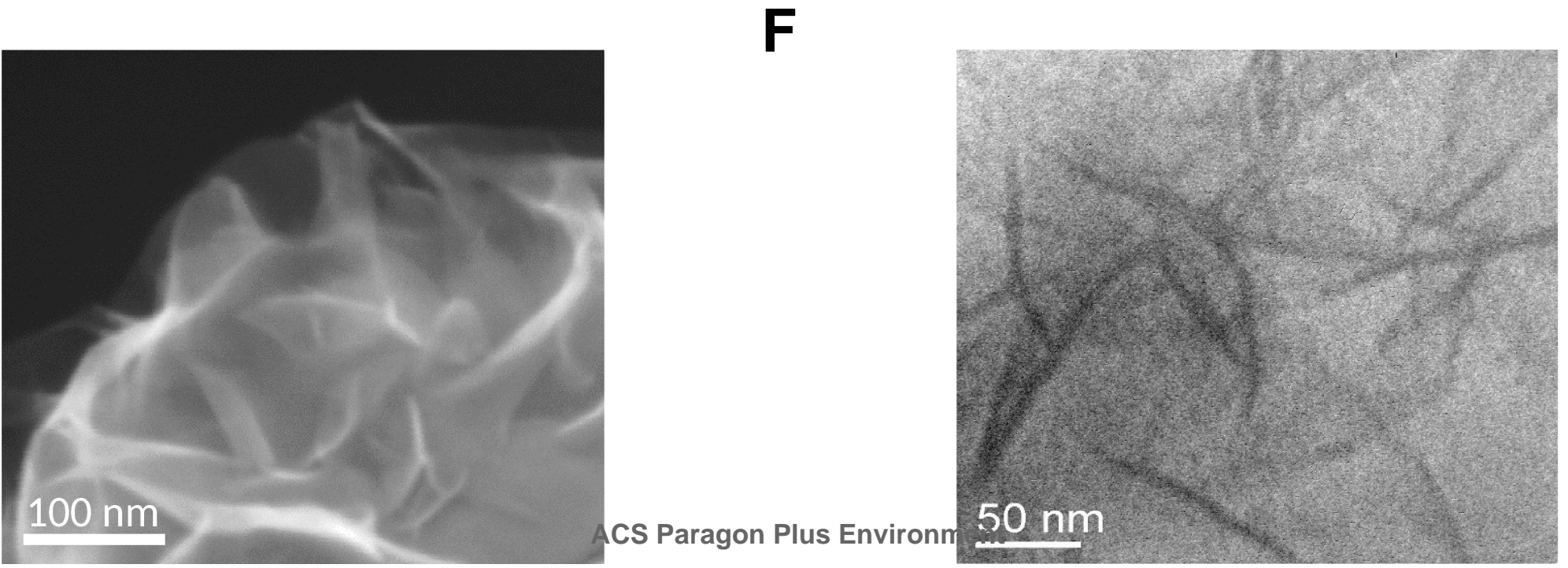

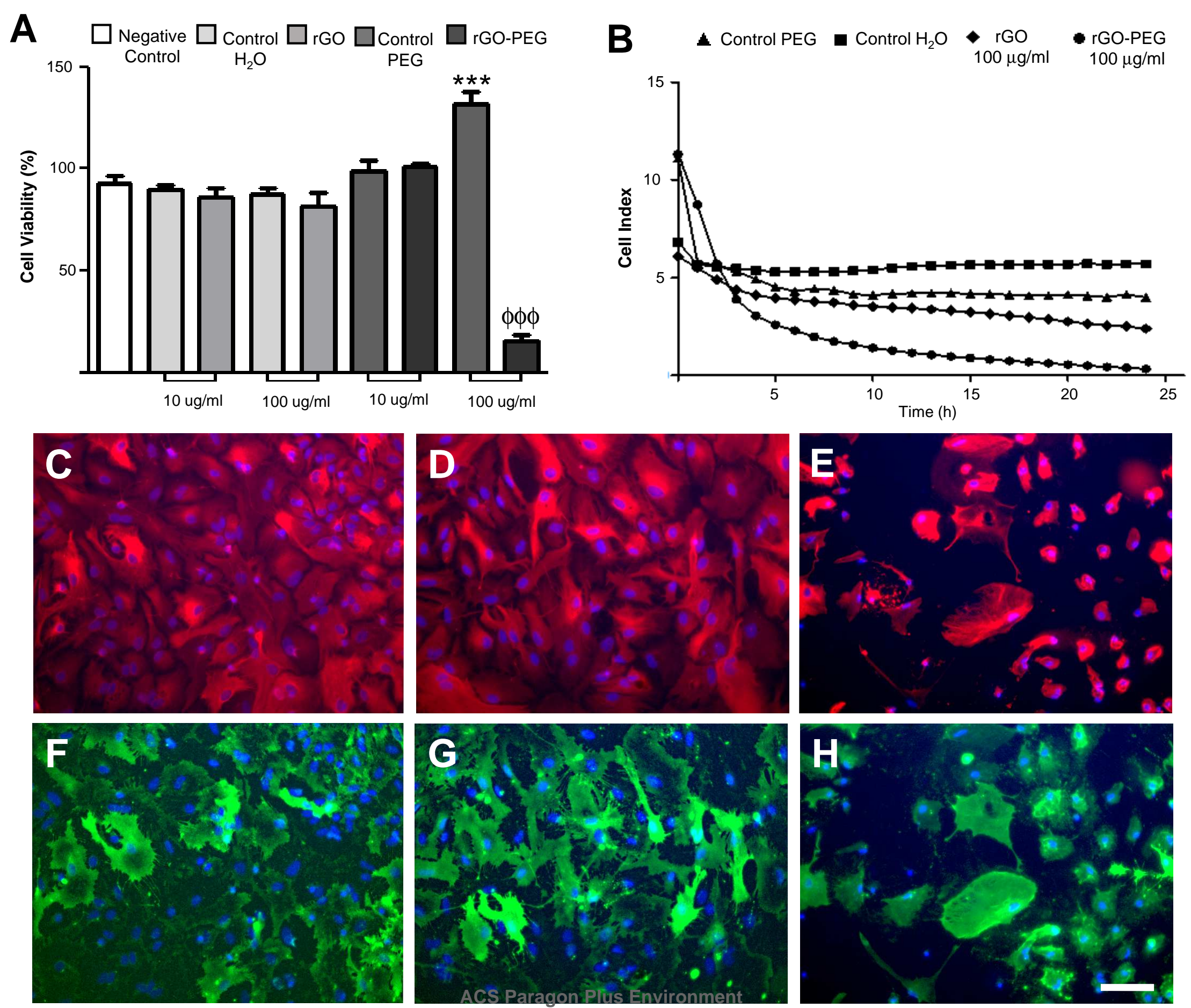

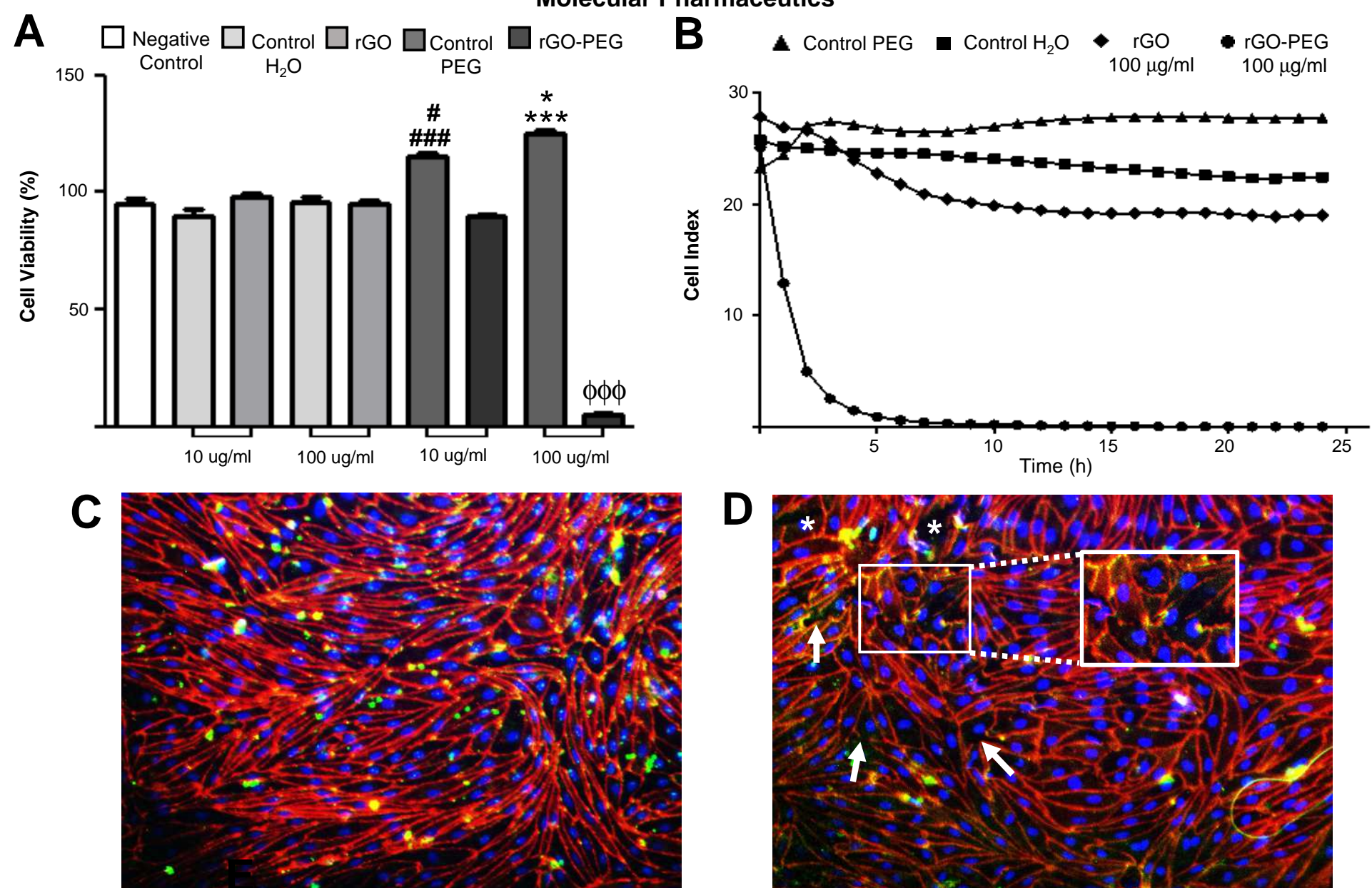

D

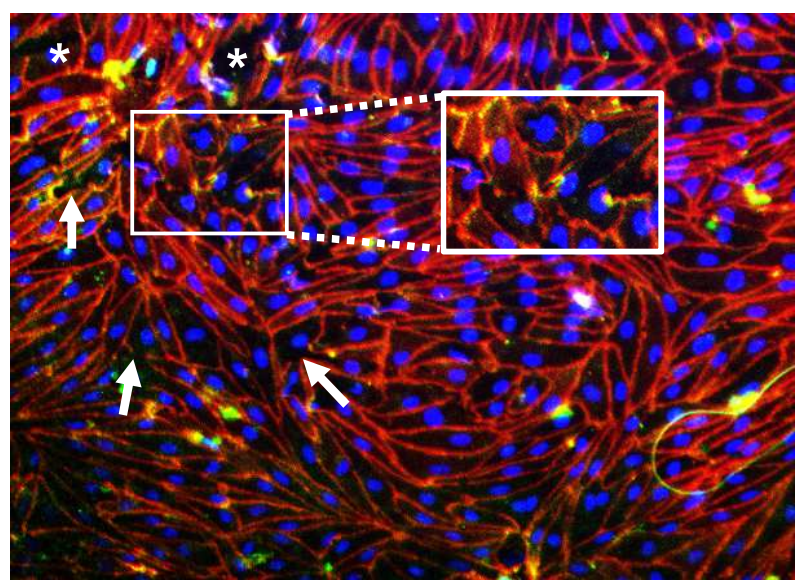

E

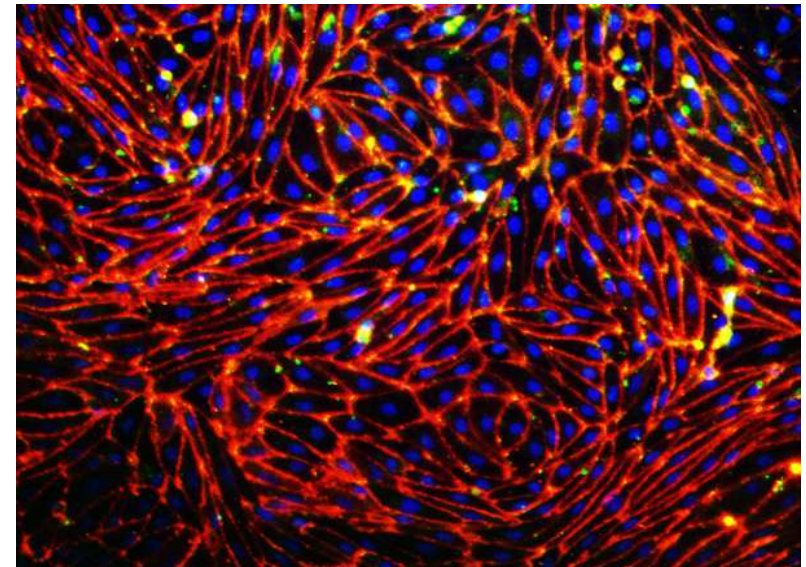

F

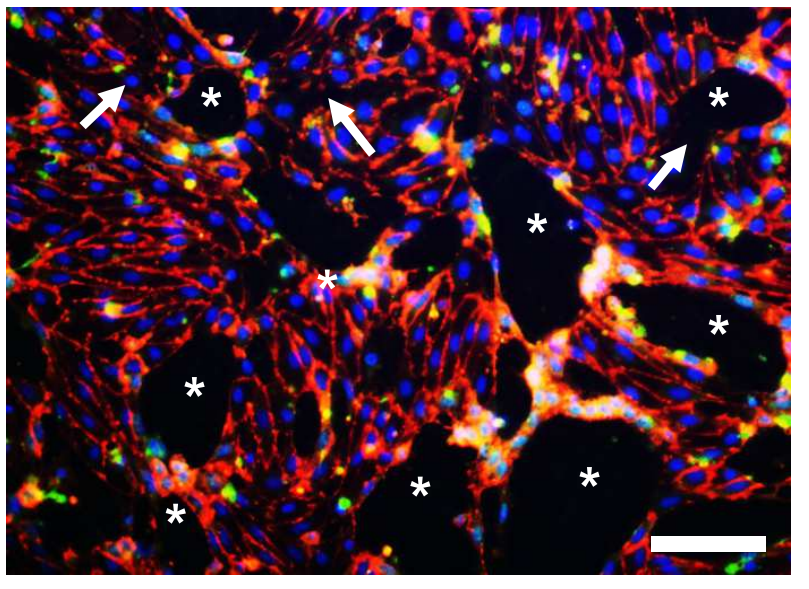

ACS Paragon Plus Environment 
A

$65 \mathrm{kDa}$

$42 \mathrm{kDa}$

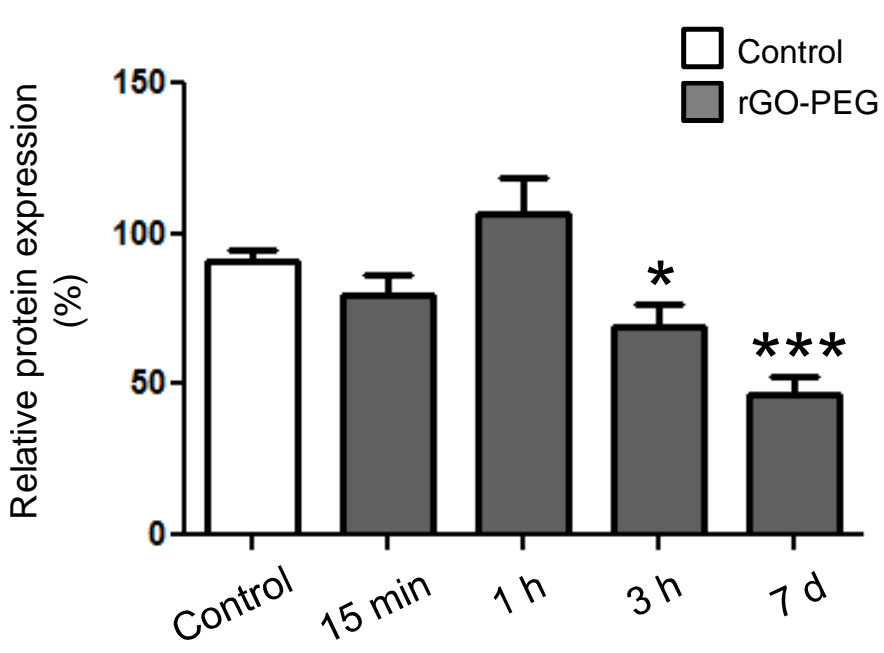

C

200 kDa

$42 \mathrm{kDa}$

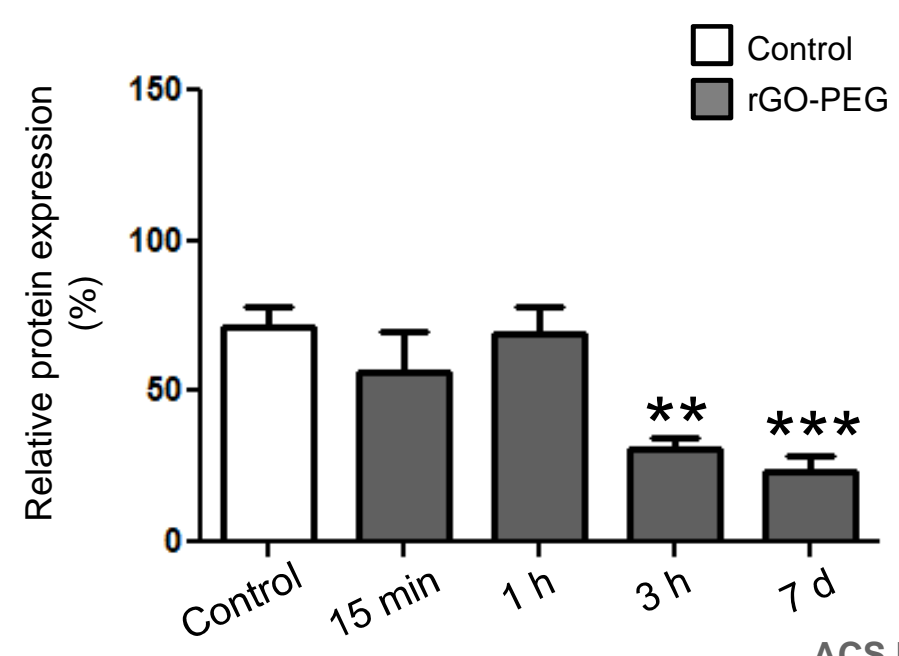

Molecular Pharmaceutics

B

\section{Occludin}

$\beta$ - actin

$42 \mathrm{kDa}$

$\beta$-catenin

$\beta$ - actin

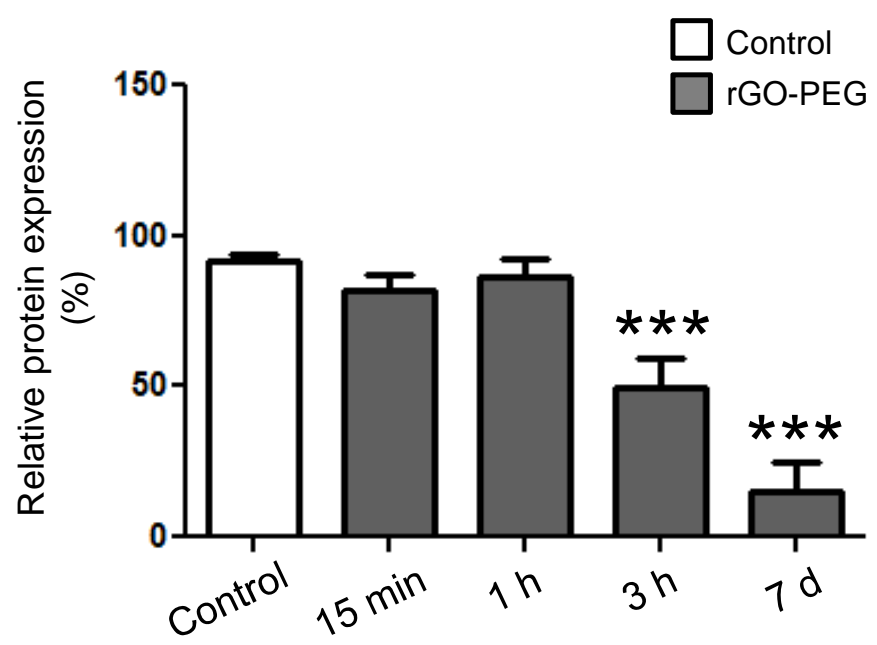

\section{Laminin}

$\beta$ - actin 


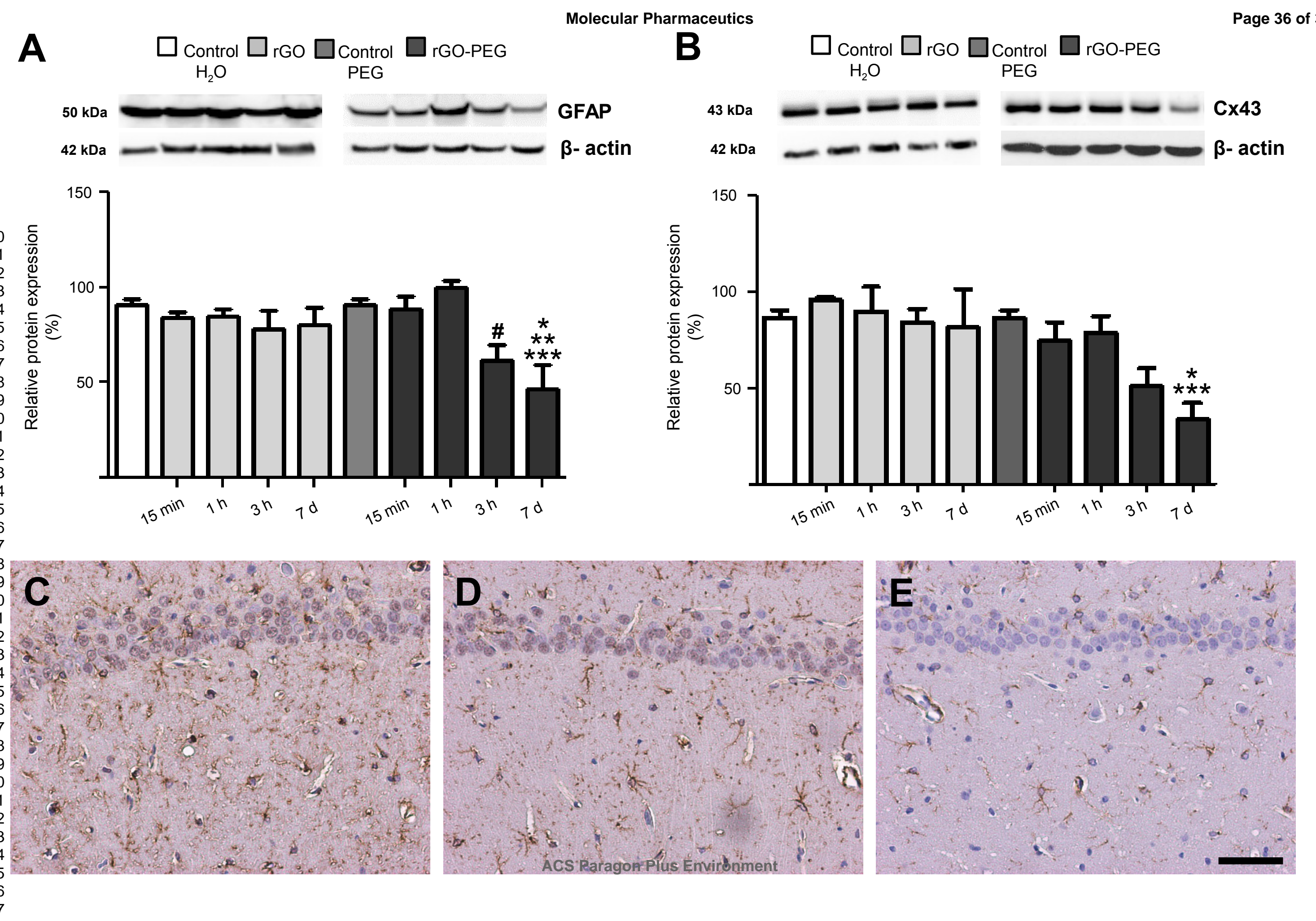




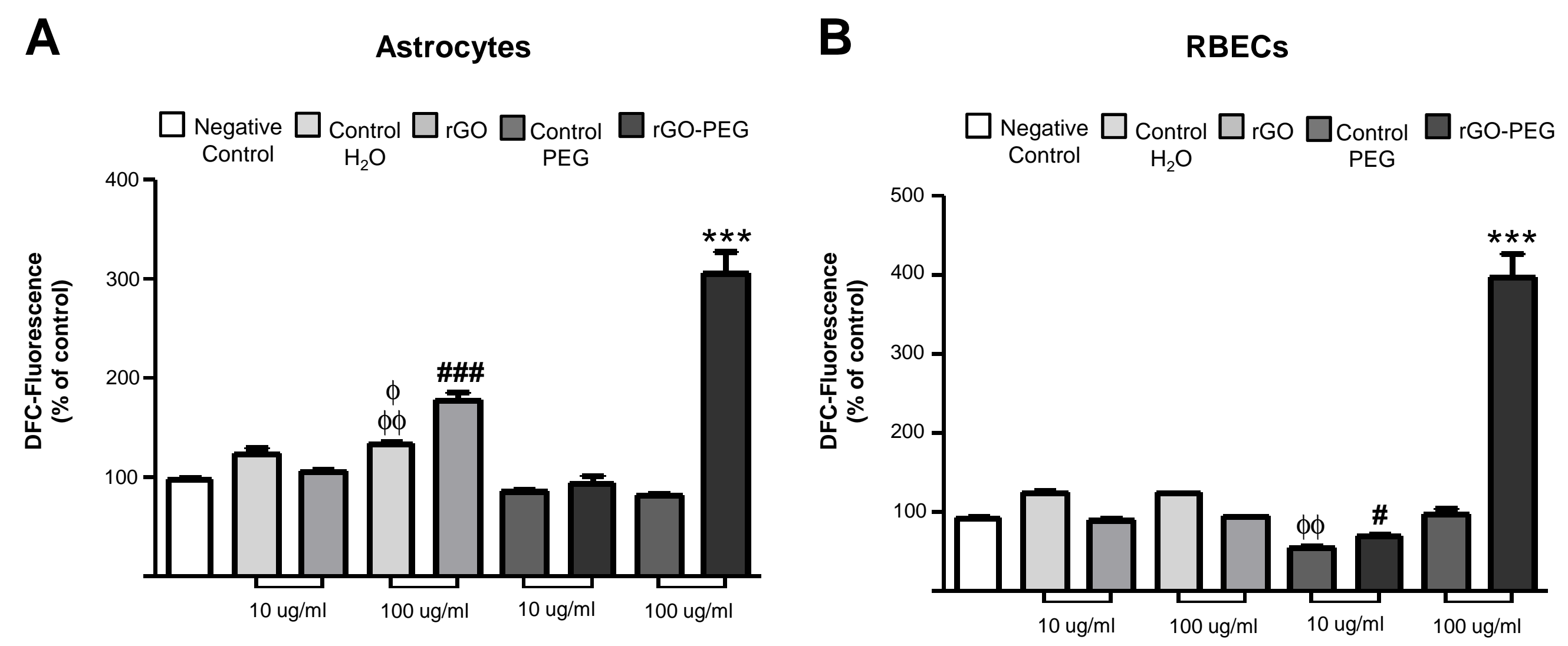


A

$50 \mathrm{kDa}$

$42 \mathrm{kDa}$

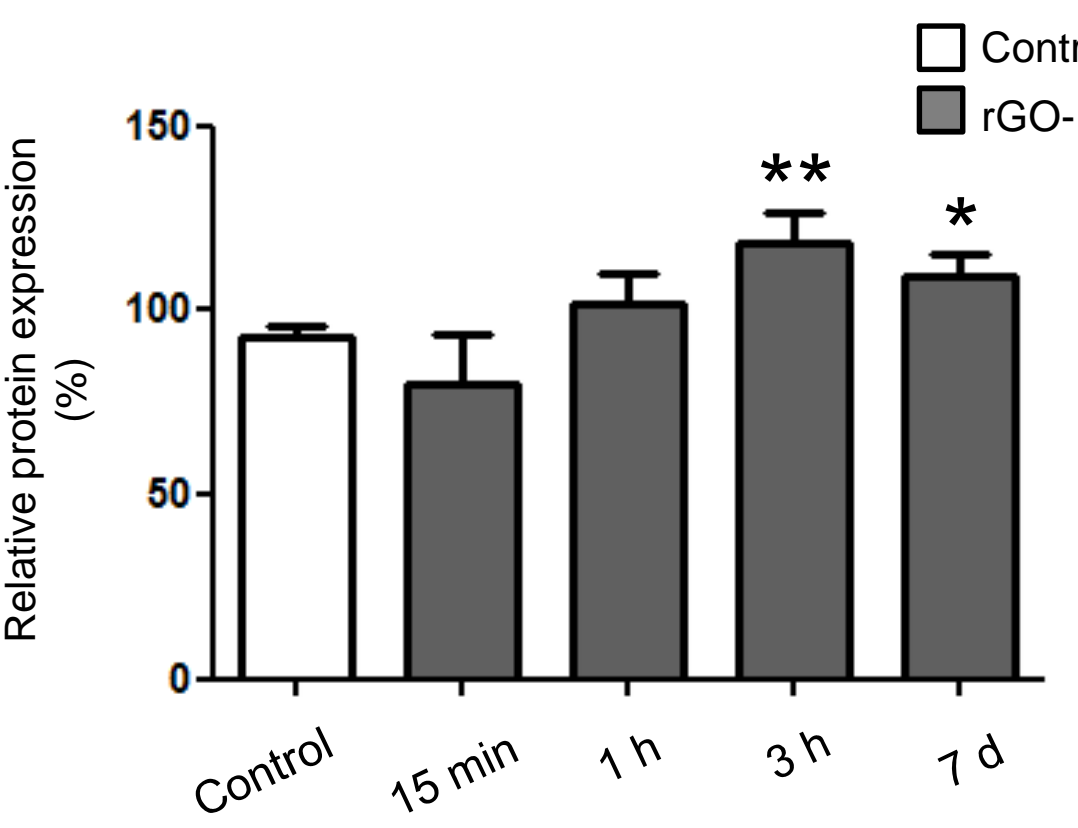

B

Catalase

$\beta$ - actin

$42 \mathrm{kDa}$

SOD-1
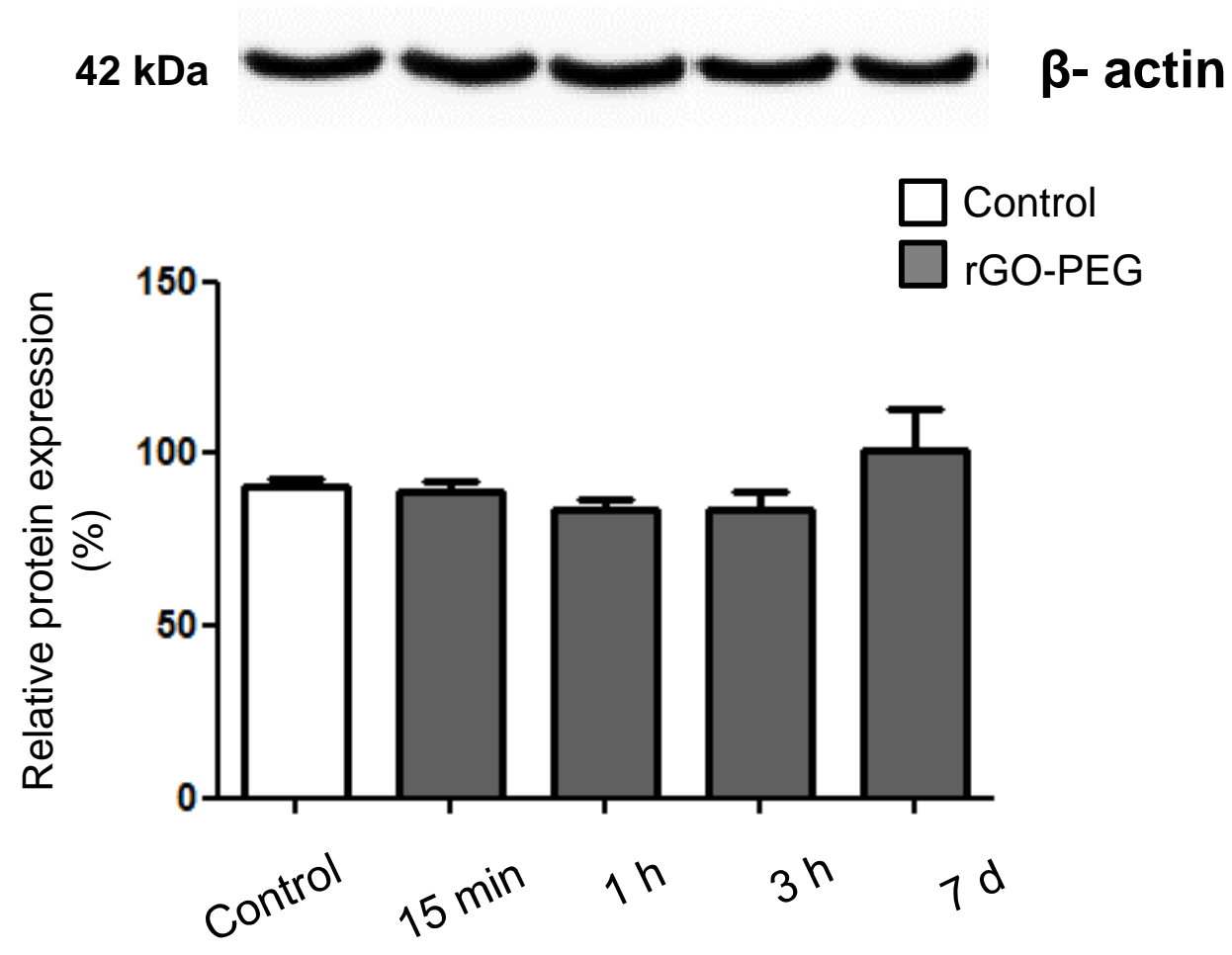


1
2
3
4
5
6
7
8
9
10
11
12
13
14
15
16
17
18
19
20
21
22
23
24
25
26
27
28
29
30
31
32
33
34
35
36
37
38
39
40
41
42
43
44
45
46
47
48
49
50
51
52
53
54
55
56
57
58
60

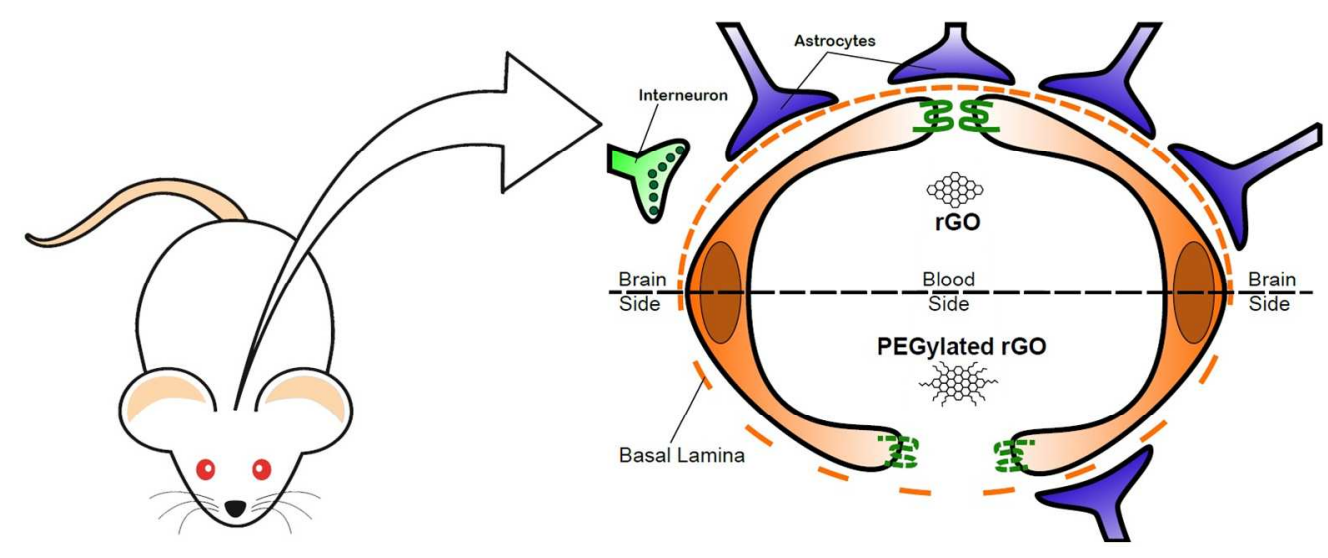

Graphical abstract

$417 \times 169 \mathrm{~mm}(96 \times 96 \mathrm{DPI})$ 